\title{
Iglesias y dinámicas sociopolíticas en el paisaje gallego de los siglos V-VIII
}

\author{
José Carlos Sánchez Pardo \\ Universidad de Santiago de Compostela
}

RESUMEN: A partir de la recopilación y análisis previo de las evidencias arqueológicas conocidas sobre edificios eclesiásticos en Galicia entre el fin del Imperio romano y la consolidación del Reino Astur y de su papel en el paisaje, se reflexiona aquí sobre los procesos sociales que estas fundaciones parecen reflejar en cada momento. El objetivo principal no es tanto el de ofrecer un estudio exhaustivo de la sociedad ni la vida eclesiástica de este período, sino el de reflexionar desde una perspectiva amplia y comparativa sobre el significado e importancia de las fundaciones de iglesias entre los siglos V y VIII en esta zona «periférica» del mundo tardoantiguo y altomedieval. Desde esta perspectiva podemos distinguir dos grandes etapas que corresponden, aproximadamente, a dos grandes procesos y contextos históricos. En primer lugar, el apogeo de los poderes supralocales, especialmente episcopales, en relación con la pervivencia de las estructuras socioeconómicas tardorromanas, y su control de la construcción de iglesias hasta aproximadamente la mitad del siglo VII. Posteriormente, el definitivo fin del paisaje tardorromano y la fragmentación política que lo acompaña sacarán a la luz un mayor protagonismo de las élites locales en la creación de iglesias. Este cambio se representa principalmente en la figura de los monasterios, como focos de estabilización en esta etapa de transición sociopolítica.

\section{PALABRAS CLAVE: Iglesias; Galicia; Tardoantigüedad; obispos; paisa- je tardorromano; monasterios.}

Churches Buildings and Socio-Political Dynamics in the Galician Landscape in the V $^{\text {th }}$-VIII ${ }^{\text {th }}$ Centuries

ABSTRACT: Following a previous collection and analysis of the archaeological evidences about church buildings in Galicia between the end of the Roman Empire and the consolidation of the Astur Kingdom, and their 
role in the landscape, this work focuses on the social processes that these foundations seems to reflect along time. The main objective is not to offer a comprehensive study of society and church life of this period but, rather, to reflect from a broad and comparative perspective on the meaning and importance of the foundations of churches between $5^{\text {th }}-8^{\text {th }}$ centuries in this «peripheral» area of the Late Antique world. From this perspective we can distinguish two main stages that roughly correspond to two major processes and contexts. First, the peak time of supra-local powers, especially bishops, in relation to the survival of late roman economical structures, and the control of church-building until mid seventh century. Subsequently, the definitive end of the late roman landscape and the consequent political fragmentation will promove a stronger role of local elites in the creation of churches. This change is mainly represented by the monasteries, as focus of stability in this time of sociopolitical transitions.

KEY WORDS: Churches; Galicia; Late Antiquity; bishops; late roman landscape; monasteries.

\section{INTRODUCCIÓN}

\section{Planteando la cuestión: iglesias y transformaciones sociales entre la Anti- güedad y la Edad Media}

En los últimos años se está produciendo un amplio debate europeo sobre las transformaciones sociales entre el fin del mundo romano y el inicio de la consolidación del feudalismo, gracias principalmente a las aportaciones de la arqueología, que ha puesto en tela de juicio algunas de las explicaciones tradicionales de los medievalistas sobre los paisajes altomedievales ${ }^{1}$. En España este debate ha comenzado a despegar recientemente en algunas áreas, gracias principalmente a la colaboración de la arqueología de gestión y la académica, y ha tenido su manifestación principal en el estudio del poblamiento rural2 Sin embargo todavía quedan diversos temas y ámbitos de estudio por incorporar a este debate. Uno de ellos son las iglesias.

Las iglesias altomedievales no son en absoluto un tema ignorado en la bibliografía española. Al contrario, constituyen, junto con las necrópolis, uno de los elementos tradicionalmente más estudiados por la Arqueología Medieval y la Historia del Arte en nuestro país. Sin embargo, se trata en su mayoría de trabajos realizados desde perspectivas artísticas y tipológicas, que abordan

1 WICKHAM, 2005. BROGIOLO, y CHAVARRÍA, 2005. FRANCOVICH y HODGES, 2003. HAMEROW, 2002.

2 QUIRÓS CASTILLO, 2009. KIRCHNER, 28 (Salamanca, 2010). 
únicamente el edificio como monumento, al margen de su contexto, tanto físico como socioeconómico. Se hace necesario, por tanto, incorporar estas edificaciones al estudio del paisaje y las sociedades en que fueron generadas y en el que adquieren (y readquieren constantemente) su sentido ${ }^{3}$.

Desde ese punto de vista, las iglesias constituyen una plataforma histórica de especial interés para la observación de los procesos sociales en la Alta Edad Media ${ }^{4}$. Estas edificaciones son a la vez centro religioso, lugar de reunión, espacio de representación y negociación del poder, manifestación de la existencia y canalización de excedentes, reflejos de un determinado orden cultural y materializaciones de un pensamiento artístico. En ellas se intersectan múltiples agentes y niveles de actuación, dando lugar a dinámicas cuyas evidencias son susceptibles de ser exploradas arqueológicamente.

Concretamente, el proceso de creación de las primeras iglesias en el mundo rural, entre los siglos V y IX, es sin duda un fenómeno de gran interés. Al margen de la interpretación de su distinta intensidad y extensión en cada zona, es obvio que esta primera «eclesificación» por todo el antiguo Imperio refleja una transformación importante y nos acerca mejor a la geografía del poder, en sus distintas escalas, de este crucial período.

Desde estas premisas, el objetivo específico de este trabajo es el de profundizar en el conocimiento de las sociedades del noroeste de la península ibérica entre mediados del siglo V y finales del siglo VIII, a través del análisis arqueológico de la figura de las iglesias y su articulación en el paisaje generado por esas formaciones sociales. Concretamente nuestro ámbito de trabajo será la actual Galicia, aunque a nivel político acudiremos a menudo a la original Gallaecia. Se trata de una zona habitualmente considerada «periférica» y menos romanizada, que posteriormente, al unirse a los emigrantes mozárabes del sur, habría generado una peculiar formación sociopolítica que llevaría a cabo la «Reconquista». En este sentido el noroeste peninsular parece especialmente interesante como área de observación de la interacción entre dinámicas endógenas y exógenas en este gran período de transición ${ }^{5}$. Y, como hemos señalado, las edificaciones eclesiásticas son un buen indicador de estas transformaciones sociopolíticas y el reflejo de distintos grados de poder y adaptación en cada momento.

3 MORRIS, 1997. TURNER, 2006. QUIRÓS CASTILLO, 29 (Salamanca, 2011). BROGIOLO y CHAVARRÍA, 14 (Zagreb, 2008).

4 ZADORA RIO, 2005. BLAIR, 2005. CHAVARRIA ARNAU, 2009. WOOD, 2006.

5 LÓPEZ QUIROGA, 2004. 


\section{Los datos de partida y su problemática}

La base principal del estudio planteado es la recopilación y análisis de evidencias materiales de iglesias «tardoantiguas» en Galicia, es decir, aquellas encuadrables entre el siglo V y finales del VIII. Se trata de un conjunto de cincuenta casos recogidos a través de una exhaustiva revisión bibliográfica, tanto arqueológica como de la Historia del Arte. Estos casos han sido posteriormente integrados en un Sistema de Información Geográfica de otras evidencias arqueológicas del paisaje altomedieval gallego (asentamientos, necrópolis y vías de comunicación). En la tabla siguiente se recogen la localización, cronología propuesta y contexto arqueológico de cada una de estas edificaciones eclesiásticas, y en el mapa correspondiente se puede apreciar su distribución por el territorio gallego. Sería inviable, por falta de espacio, realizar aquí una descripción detallada de todas estas evidencias. Ésta, junto al estudio de sus problemáticas y perspectivas metodológicas, se puede encontrar en un reciente trabajo al que remitimos ${ }^{6}$.

En todo caso, es necesario recordar la problemática que plantean algunas de estas evidencias, especialmente en relación a su datación o encuadramiento cronocultural. Esto se debe, por un lado, a la escasez de estratigrafías precisas. Aunque las actuaciones arqueológicas relativas a iglesias altomedievales en Galicia no son necesariamente escasas, hay muy pocos casos excavados con criterios rigurosos y menos aun los que se pueden adscribir con un cierto nivel de seguridad al período comprendido entre los siglos V y VIII. Entre ellos podemos destacar sin duda los yacimientos de Adro Vello ${ }^{7}$, Eirexa Vella de Bares ${ }^{8}$ y Ouvigo ${ }^{9}$, que gozaron de una excavación relativamente amplia y una publicación más o menos detallada. Junto a estos estudios más claros y mejor conocidos (aunque no exentos de problemas), contamos en Galicia con otra serie de excavaciones también relativamente recientes y/o estratigráficamente planteadas, que sin embargo no han llegado a demostrar con certeza la existencia de una estructura religiosa en este período tardoantiguo, aunque la mayor parte de los indicios así parecen apuntarlo. Este sería el caso, por ejemplo, de Currás-Tomiño ${ }^{10}$, San Xiao-Pipín ${ }^{11}$, Cidadela ${ }^{12}$, Vigo o Morai$\mathrm{me}^{13}$. Finalmente, debemos referirnos a otra serie de yacimientos importantes

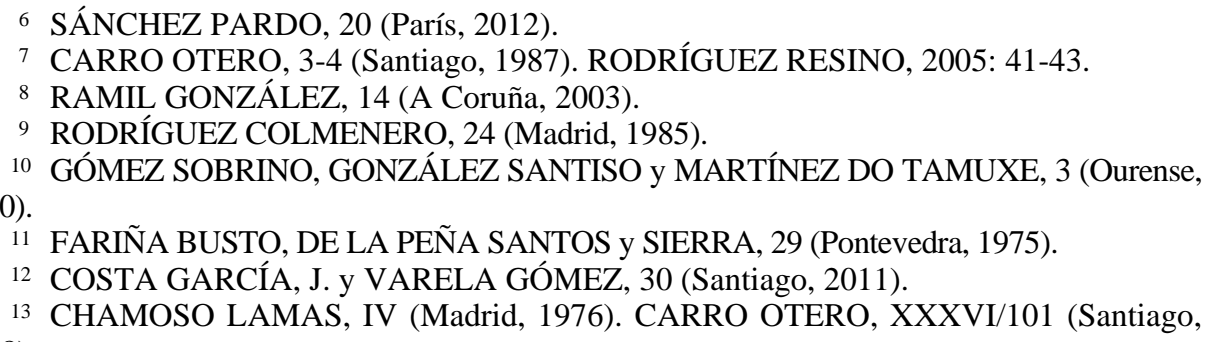


y conocidos, pero que fueron excavadas en los años cincuenta y sesenta del siglo pasado, sin seguir, en la mayor parte de los casos criterios estratigráficos y sobre todo, sin dejar prácticamente documentación sobre dichas excavaciones. De esta manera se hace casi imposible evaluar los resultados, su fiabilidad y su representatividad, sobre todo teniendo en cuenta que en las últimas décadas se han producido muchos cambios en la interpretación de ciertos elementos que estos arqueólogos, principalmente M. Chamoso Lamas, usaban como datadores (por ejemplo, las famosas «laudas de estola suevas»). En todo caso, hay en todas estas iglesias muchas ideas de interés para nuestro trabajo, por ejemplo en Iria Flavia ${ }^{14}$, San Bartolomé de Rebordáns ${ }^{15}$, San Martiño de Mondoñedo ${ }^{16}$, Bretoña ${ }^{17}$ o Santa Eulalia de Tines ${ }^{18}$. Por otro lado, hay que referirse también a la problemática suscitada por el debate sobre las iglesias «visigodas», impulsado principalmente por L. Caballero Zoreda ${ }^{19}$. Esta intensa polémica, que ha evolucionado pero aún no ha llegado a un consenso, discute si aspectos de la arquitectura y estilos «visigodos» pertenecerían realmente a un contexto posterior a la conquista musulmana del 711. Esto podría redefinir considerablemente los marcos y contextos sociales bajo los que se interpreta este período ${ }^{20}$, introduciendo de nuevo la necesidad de factores y fuerzas exógenas para explicar la evolución del norte peninsular.

Por tanto, aunque todos los casos aquí recogidos están sustentados por bibliografía especializada, y solamente representan los ejemplos más fiables de una lista más amplia de posibles casos, la cronología y adscripción de alguna de dichas iglesias puede ser puesta en duda. Por ello, añadimos una valoración del grado de «certeza» (alto, medio o bajo) de las evidencias disponibles en cada caso para realizar su adscripción cronocultural ${ }^{21}$. Y sobre todo, como hemos dicho, trataremos de entender cada caso dentro de su contexto histórico y arqueológico específico. Creemos que esto puede ayudar a desenredar un

14 SUÁREZ OTERO, 2004.

15 CHAMOSO LAMAS y FILGUEIRA VALVERDE, 4 (Madrid, 1976).

16 CHAMOSO LAMAS, XXI (Braga, 1967); 4 (Madrid, 1975).

17 CHAMOSO LAMAS, 4 (Madrid, 1975).

18 CHAMOSO LAMAS, II (Barcelona, 1965); 16/1-4 (Santiago, 1971).

19 CHAVARRIA, 18/2 (Londres, 2010). UTRERO, 54 (Londres, 2010). CABALLERO y MATEOS, 2000.

20 A pesar de lo cual el debate permanece anclado únicamente en términos materiales y artísticos.

21 De manera general, consideramos con certeza «alta» aquellas evidencias materiales datadas con precisión y seguridad en algún momento determinado de este período. Certeza «media» incluye las evidencias que muy probablemente se pueden datar dentro de este período, pero presentan algún problema específico de definición o precisión. Certeza «baja» se refiere a evidencias con posibilidades de encuadrarse en este período pero que no se han podido demostrar plenamente. Como se ha señalado, hemos dejado de lado otra amplia serie de potenciales casos que, por el momento, no cuentan con un respaldo arqueológico mínimamente sólido. 
poco el mencionado debate sobre las iglesias visigodas. Pretendemos así enmarcar la aparición de las primeras iglesias del noroeste peninsular en el ámbito europeo de las transformaciones de este período, calibrando su posible adecuación a las categorías de «Tardoantigüedad» y «largo siglo VIII»"22 en las que se definen y reformulan las relaciones sociales, económicas y políticas que marcarán el origen del feudalismo.

TABla 1: ELENCO DE EVIDENCIAS MATERIALES DE IGLESIAS EN GALICIA ENTRE LOS SIGLOS V Y VIII

\begin{tabular}{|l|l|l|l|l|}
\hline \multicolumn{1}{|c|}{ NOMBRE } & Municipio & $\begin{array}{c}\text { Cronología } \\
\text { inicial } \\
\text { propuesta }\end{array}$ & $\begin{array}{c}\text { Certeza } \\
\text { de evi- } \\
\text { dencias }\end{array}$ & $\begin{array}{l}\text { Contexto arqueológico previo } \\
\text { (iglesia superpuesta a) }\end{array}$ \\
\hline A Ermida & Quiroga & Siglos V-XI & Baja & $\begin{array}{l}\text { Posible asentamiento romano } \\
\text { del s. IV }\end{array}$ \\
\hline Adro Vello & O Grove & Siglo VII & Alta & $\begin{array}{l}\text { Villa romana costera (ss. I- } \\
\text { IV), necrópolis desde V-VII }\end{array}$ \\
\hline Capela dos Martores & Valga & Siglos VI-VIII & Baja & No constatado \\
\hline Cidadela & Sobrado & Siglos VI-VIII & Alta & $\begin{array}{l}\text { Campamento romano (ss. II- } \\
\text { IV) y ocupación del V }\end{array}$ \\
\hline Córgomo & Vilamartín & Fines del s. VI & Baja & Posible asentamiento romano \\
\hline Currás-Tomiño & Tomiño & Siglos VI-XI & Baja & $\begin{array}{l}\text { Castro, necrópolis y asenta- } \\
\text { miento rural hasta s. V }\end{array}$ \\
\hline Eirexa Vella de Bares & Mañón & Siglo VII & Alta & $\begin{array}{l}\text { Factoría costera (ss. IV-VI) y } \\
\text { necrópolis desde s. VI }\end{array}$ \\
\hline Ferreira de Pallares & Guntín & Siglo VII-IX & Baja & No constatado \\
\hline Iria Flavia & Padrón & Siglos III-V & Alta & $\begin{array}{l}\text { Posible domus urbana (¿eccle- } \\
\text { siae?) bajorromana }\end{array}$ \\
\hline Ouvigo & Blancos & Siglos IV-V & Alta & Villa romana \\
\hline Panxón & Nigrán & Fines del s. VII & Media & $\begin{array}{l}\text { Villa-factoría romana costera } \\
\text { y necrópolis de ss. IV-VI }\end{array}$ \\
\hline Petín & Petín & Mitad del s. VI & Media & $\begin{array}{l}\text { Asentamiento romano y tardo- } \\
\text { rromano }\end{array}$ \\
\hline Saamasas & Lugo & $\begin{array}{c}\text { Fines VI- } \\
\text { inicios VII }\end{array}$ & Media & No constatado \\
\hline $\begin{array}{l}\text { San Adrián de Amia- } \\
\text { doso }\end{array}$ & Allariz & Siglos IV-X & Baja & $\begin{array}{l}\text { Posible mausoleo bajorroma- } \\
\text { no (s. IV) }\end{array}$ \\
\hline San Antolín de Toques & Toques & Siglos VII-X & Baja & No constatado \\
\hline $\begin{array}{l}\text { San Bartolomé de } \\
\text { Rebordáns }\end{array}$ & Siglos VII-IX & Media & $\begin{array}{l}\text { Villa suburbana hasta s. V-VI } \\
\text { y posterior necrópolis }\end{array}$ \\
\hline San Estevo da Barcia & Siglos VI-XI & Baja & No constatado \\
\hline
\end{tabular}

22 LYSE HANSEN, y WICKHAM, 2000. 


\begin{tabular}{|c|c|c|c|c|}
\hline NOMBRE & Municipio & $\begin{array}{c}\text { Cronología } \\
\text { inicial } \\
\text { propuesta }\end{array}$ & $\begin{array}{c}\text { Certeza } \\
\text { de evi- } \\
\text { dencias }\end{array}$ & $\begin{array}{l}\text { Contexto arqueológico previo } \\
\text { (iglesia superpuesta a) }\end{array}$ \\
\hline San Estevo de Parga & Guitiriz & Siglo VII & Baja & Castro romanizado \\
\hline San Martín de Prado & Lalín & Siglos VI-XI & Baja & No constatado \\
\hline $\begin{array}{l}\text { San Martiño de Mon- } \\
\text { doñedo }\end{array}$ & Foz & Siglo VI-IX & Baja & Probable villa romana \\
\hline San Pedro de Carcacía & Padrón & Fines del s. VII & Baja & No constatado \\
\hline San Pedro de Leis & Muxía & Siglo VI & Baja & No constatado \\
\hline San Pedro de Rocas & Esgos & Siglo VI-XI & Media & No constatado \\
\hline San Roque de Lugo & Lugo & Inicios del s. VII & Alta & Necrópolis romana (ss. I-V) \\
\hline $\begin{array}{l}\text { San Sadurniño de } \\
\text { Goiáns }\end{array}$ & $\begin{array}{l}\text { Porto do } \\
\text { Son }\end{array}$ & Siglos VII-IX & Media & $\begin{array}{l}\text { Villa-factoría costera romana } \\
\text { y mausoleo del s. V-VI }\end{array}$ \\
\hline San Salvador de Samos & Samos & Fines del s. VI & Alta & No constatado \\
\hline $\begin{array}{l}\text { San Salvador de Sou- } \\
\text { tomerille }\end{array}$ & $\begin{array}{c}\text { Castrover- } \\
\text { de }\end{array}$ & Siglos VIII-IX & Media & No constatado \\
\hline $\begin{array}{l}\text { San Vicente (¿do Mi- } \\
\text { ño?) }\end{array}$ & $\begin{array}{c}\text { Nogueira } \\
\text { de R. }\end{array}$ & Siglo VII & Baja & $\begin{array}{l}\begin{array}{l}\text { No constatada (aunque se } \\
\text { halló tégula romana) }\end{array} \\
\end{array}$ \\
\hline San Vicente de Agrade & Chantada & Siglos VI-XI & Baja & Villa bajorromana del siglo IV \\
\hline San Xiao de Moraime & Muxía & Siglos VII-XI & Media & $\begin{array}{l}\text { Villa romana y necrópolis de } \\
\text { ss. V-XI }\end{array}$ \\
\hline San Xiao de Trebo & Cariño & Siglo VII-XI & Baja & $\begin{array}{l}\text { Villa-factoría costera tardo- } \\
\text { rromana }\end{array}$ \\
\hline San Xiao-Pipín & Cangas & Siglo VI-XI & Baja & $\begin{array}{l}\text { Villa costera bajorromana del } \\
\text { s. IV }\end{array}$ \\
\hline $\begin{array}{l}\text { San Xoán de Baños de } \\
\text { Bande }\end{array}$ & Bande & Siglos VI-XI & Baja & Necrópolis de inicios del s. VI \\
\hline San Xoán de Campo & Lugo & Siglos IV-X & Baja & No constatado \\
\hline San Xoan de Vilaronte & Foz & Fines del s. VII & Media & No constatado \\
\hline Santa Comba de Bande & Bande & Fines del s. VII & Alta & $\begin{array}{l}\text { Posible monumento funerario } \\
\text { tardorromano }\end{array}$ \\
\hline $\begin{array}{l}\text { Santa Eulalia de Bóve- } \\
\text { da }\end{array}$ & Lugo & Siglos IV-IX & Media & $\begin{array}{l}\begin{array}{l}\text { Ninfeo de una villa romana } \\
\text { del s. III-IV }\end{array} \\
\end{array}$ \\
\hline Santa Eulalia de Tines & Vimianzo & Siglos VI-IX & Baja & $\begin{array}{l}\text { Villa bajorromana y necrópo- } \\
\text { lis ss. IV-XII }\end{array}$ \\
\hline Santa María de Bretoña & A Pastoriza & Siglo VI & Media & $\begin{array}{l}\text { Castro-asentamiento rural } \\
\text { romano }\end{array}$ \\
\hline Santa María de Lugo & Lugo & Siglo IV & Alta & Posible domus ecclesiae urbana \\
\hline Santa María de Mosteiro & Guntín & Fines del s. VIII & Media & No constatado \\
\hline Santa María de Muxía & Muxía & Siglos VII-XI & Baja & No constatado \\
\hline Santa María de Xanza & Valga & Siglos VI-XI & Baja & No constatado \\
\hline Santa María Nai & Ourense & Siglos IV-V & Alta & Posible domus ecclesiae urbana \\
\hline Santiago de Mens & Malpica & Siglos VII-X & Baja & $\begin{array}{l}\text { Posible oratorio-mausoleo de } \\
\text { ss. V-VII }\end{array}$ \\
\hline
\end{tabular}




\begin{tabular}{|l|l|c|c|l|}
\hline \multicolumn{1}{|c|}{ NOMBRE } & Municipio & $\begin{array}{c}\text { Cronología } \\
\text { inicial } \\
\text { propuesta }\end{array}$ & $\begin{array}{c}\text { Certeza } \\
\text { de evi- } \\
\text { dencias }\end{array}$ & $\begin{array}{c}\text { Contexto arqueológico previo } \\
\text { (iglesia superpuesta a) }\end{array}$ \\
\hline Santiago de Proendos & Pantón & Siglo VIII-X & Baja & Probable villa romana \\
\hline Setecoros & Valga & Siglos VI-VII & Media & Asentamiento tardorromano \\
\hline Temes & Carballedo & Inicios del s. IX & Media & Mausoleo cristiano del siglo IV \\
\hline Vigo (Vicus Elanei) & Vigo & $\begin{array}{c}\text { Fines VI-mitad } \\
\text { VII }\end{array}$ & Media & $\begin{array}{l}\text { Villa-factoría comercial coste- } \\
\text { ra romana (ss. II-VII) }\end{array}$ \\
\hline Xagoaza & O Barco & Fines del s. VI & Baja & No constatado \\
\hline
\end{tabular}

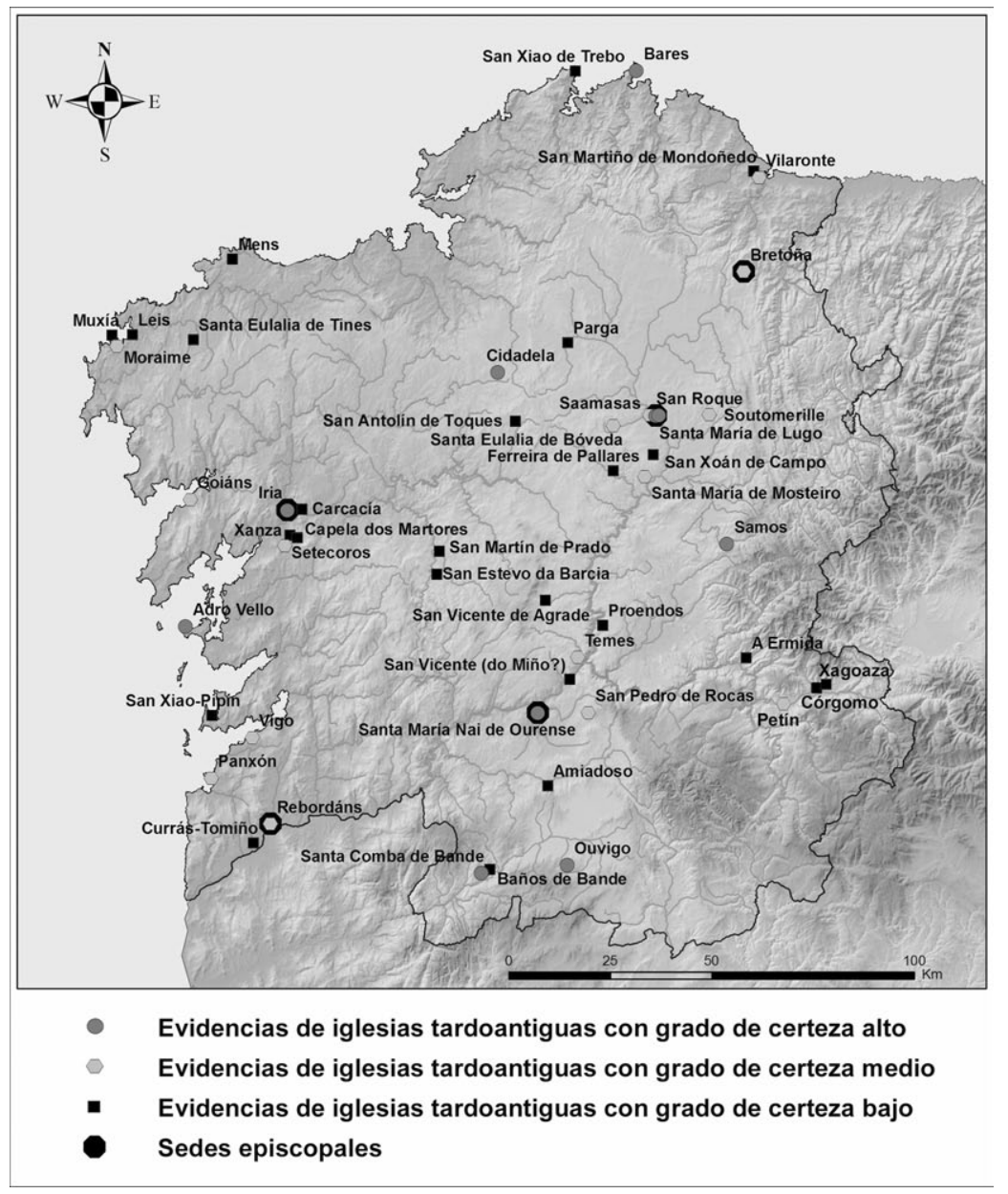

FIGURA 1: MAPA DE DISTRIBUCIÓN DE LAS EVIDENCIAS MATERIALES DE IGLESIAS EN GALICIA ENTRE LOS SIGLOS V Y VIII. 


\section{PolARIZACIÓN SOCIAL Y ECONÓMICA EN EL CONTEXTO DE LA CRISTIANIZA- CIÓN RURAL (CA. 450-650 D. C.)}

\section{Las transformaciones de la Gallaecia tardorromana}

¿Cuál es el contexto de nacimiento de las primeras iglesias en el Noroeste peninsular entre los siglos V y VII? En los últimos años, la visión catastrofista de este período ha dado paso a una percepción más positiva pero sobre todo más compleja del mismo. En el caso de Galicia, aunque aún son necesarios nuevos estudios, hay que hablar de la pervivencia e incluso dinamismo de muchas de las estructuras socioeconómicas tardorromanas, aunque entendidas dentro de un contexto de transformaciones. Varios factores explican esta situación.

En primer lugar, Gallaecia, como zona «periférica» en la parte más occidental del Imperio romano, no había desarrollado una imbricación tan profunda en sus estructuras políticas y económicas como otras áreas peninsulares. De manera especial, en el noroeste nunca tuvo demasiado peso el clásico binomio campo-ciudad, sino que los «aglomerados secundarios» ${ }^{23}$ serán los articuladores de (y para) un mayoritario mundo rural ${ }^{24}$. La crisis económica del bajo Imperio tampoco parece haber sido tan acusada en esta zona, sino que se mantienen en funcionamiento unos circuitos económicos propios, menos amplios pero igualmente eficaces y adaptados. Esto no implica, como habitualmente se ha sostenido, que no haya existido «romanización» en el noroeste, ni que ésta haya sido menos importante. Se trató sin duda de un proceso lento y prolongado, pero a la vez profundo e intenso, que terminó dando lugar a la sociedad galaicorromana ${ }^{25}$.

En segundo lugar, también hay que relativizar y reinterpretar el significado del llamado «Reino Suevo» y del aporte germánico en Gallaecia. Los contingentes poblacionales suevos que se asentaron en el noroeste peninsular a inicios del siglo V fueron cuantitativamente pocos, y se concentraron casi exclusivamente en las zonas urbanas del triángulo Tuy-Braga-Oporto ${ }^{26}$. Los suevos se integrarían rápidamente y de forma relativamente pacífica a la forma de vida de las élites galaicorromanas ${ }^{27}$. El Reino Suevo debe entenderse más como una estructura sociopolítica que engloba a una serie de sectores, intereses y dinámicas tardoantiguas de esta zona que en términos étnicos o políti-

23 PÉREZ LOSADA, 2002.

24 SÁNCHEZ PARDO, LXV (Salamanca, 2010). ARIAS VILAS y VILLA VALDÉS, 2005.

25 ARIAS VILAS, 1992. BALIÑAS, 1992. NOVO GUISÁN, 1992.

26 DÍAZ MARTÍNEZ, 1993. ARIAS VILAS, 1997.

27 DÍAZ MARTÍNEZ, 1993: 209-226. DÍAZ, 1997.

Hispania, 2013, vol. LXXIII, nº. 243, enero-abril, págs. 11-50, ISSN: 0018-2141, e-ISSN: 1988-8368, doi: 10.3989/hispania.2013.002 
cos. En todo caso, las capacidades de estos sectores no deben minusvalorarse y de hecho, la capital de Gallaecia en los siglos V y VI, Braga, presenta una especial vitalidad y protagonismo dentro del contexto de la península ibérica. La integración en el Reino Visigodo a finales del siglo VI tampoco parece especialmente traumática y Gallaecia no sufrirá cambios políticoadministrativos importantes hasta mediados del VII ${ }^{28}$.

Como resultado de estos factores, la periférica Gallaecia aparece, paradójicamente, en estos siglos, como un área especialmente dinámica y en contacto con el resto del mundo tardorromano. Desde el punto de vista arqueológico, la cultura material mayoritaria de este período es plenamente romana ${ }^{29} \mathrm{y}$ las evidencias de contactos comerciales son particularmente intensas ${ }^{30}$, especialmente por vía marítima. Los recientes e importantes hallazgos en Vigo indican un importante comercio a larga distancia en los siglos V, VI y la primera mitad del VII que transitaba y se detenía en Galicia y la conectaba con Próximo Oriente y Norte de África, así como con la Galia y el suroeste de Gran Bretaña ${ }^{31}$. Entre esos productos viajaban mercancías de lujo (vajillas finas, ungüentarios, producciones artísticas en mármol como capiteles, ricos sarcófagos, canceles...), lo que nos informa de la existencia en el noroeste de unas élites que, aunque minoritarias, eran capaces de costear dichos productos $^{32}$. Igualmente, al analizar las producciones escritas de autores galaicos de la época, como Hidacio, se aprecia una cultura latina amplia ${ }^{33}$, y claras conexiones con otras áreas del Imperio. Concretamente, la influencia bizantina en Gallaecia es especialmente importante en este período, sobre todo a nivel religioso, con numerosas advocaciones de procedencia oriental ${ }^{34}$, testimonios de peregrinaciones a Tierra Santa e influencias en el arte eclesiástico. La relación con la Galia se manifiesta principalmente en el ámbito político, con distintas alianzas del Reino Suevo con los merovingios citadas por Gregorio de Tours, sin olvidar la importancia político-religiosa de San Martín de Dumio (venido de Panonia a través de la Galia) y la extensión de advocaciones galas como Santa Columba y San Martín de Tours ${ }^{35}$.

Todo esto no pretende negar, sino contextualizar, una serie de evidentes transformaciones durante este período reflejadas tanto en el registro material como en el escrito. Se trata más bien de reflexionar sobre la necesidad de in-

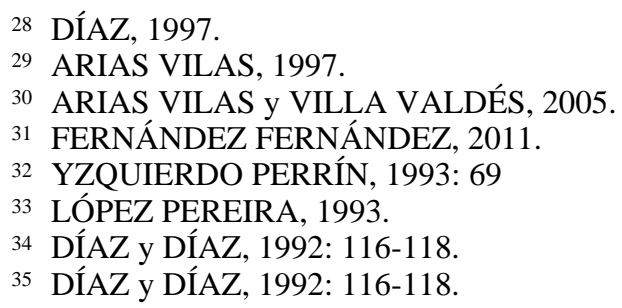


terpretaciones más complejas y articuladas sobre el mismo. En efecto, durante este período asistimos a una desarticulación del sistema económico global romano, lo que se traduce sin duda en distintos grados de crisis según la imbricación de cada grupo y zona en dicho sistema ${ }^{36}$. Por otro lado, se trata de una desarticulación progresiva, con distintas fases, y que permite, o incluso genera, vectores de dinamismo dentro de la misma. Los ejemplos más evidentes y que más nos interesan aquí son los relativos a la estructura de poblamiento y las dinámicas sociopolíticas.

Durante este período, entre la mitad del siglo V y la mitad del siglo VII, asistimos al declive de muchos asentamientos y núcleos típicamente romanos, como ciudades, aglomerados secundarios, vici o villae. Sin embargo, actualmente sabemos que, a pesar de una cierta retracción, los principales núcleos urbanos como Lugo, Tui, Iria u Ourense continúan ocupados en los siglos siguientes, y sobre todo, seguirán ejerciendo un papel esencial como centros de residencia del poder supralocal ${ }^{37}$. Por otro lado, aunque la mayor parte de las villae, o más bien, de las áreas principales o de representación de las mismas, se abandonan en este período ${ }^{38}$, ello no implicará necesariamente el fin de la ocupación y explotación de su entorno. Tampoco hay que pensar en la desaparición o huída de las élites sino más bien en una evolución de su carácter y formas de representación ${ }^{39}$. De hecho, a la vez que algunas villae aparentemente se abandonan, otras se crean o están experimentando su mayor auge económico, lo que nos lleva a pensar, quizá, en la concentración de propiedades en unas pocas manos. Y finalmente hay que recordar que al margen de esta serie de asentamientos, habría una enorme mayoría de pequeños establecimientos agrarios distribuidos por todo el territorio galaico, que apenas han sido estudiados y que no parecen, a la luz de los escasos datos disponibles, sufrir una ruptura ni desaparición en este momento, sino que de hecho constituirán en muchos casos la base del poblamiento de los siglos siguientes ${ }^{40}$.

Un segundo aspecto central para entender los cambios del mundo tardorromano y contextualizar la consolidación de la Iglesia es el referido a los procesos sociopolíticos. La sociedad de Gallaecia de los siglos V, VI y de la primera mitad del VII, al igual que gran parte del antiguo Imperio romano se caracteriza por una tendencia a la polarización social y económica. Ésta, como tiende a ocurrir en las épocas de crisis, se basó en el acaparamiento de propiedades en unas pocas manos, aquellas clases altas que disfrutaban de recursos o contextos de partida favorables para aprovechar esa coyuntura.

36 LÓPEZ QUIROGA, 2004: 290-292.

37 ISLA FREZ, 1992. PÉREZ LOSADA, 2002.

38 RODRÍGUEZ RESINO, 2005: 173-181.

39 CHAVARRIA ARNAU, 2007: 158-159.

40 SÁNCHEZ PARDO, XXXVII (Siena, 2010). 
Esto provocará un progresivo aumento de la importancia de algunos poderes supralocales en este período, y sin duda la Iglesia, especialmente las jerarquías episcopales, residentes en el mundo urbano, serán uno de los principales protagonistas y beneficiados de este proceso. A nivel administrativo, estos poderes supralocales serán capaces de ir organizando, sobre todo en el siglo VI, una estructura territorial eficaz, basada en pequeños centros dispersos con funciones eclesiástico-administrativas ${ }^{41}$.

\section{La primera organización territorial eclesiástica}

Es en este período cuando se consolida la primera organización territorial eclesiástica en Galicia. Por supuesto ya antes hay evidencias de comunidades cristianas y del nacimiento de las primeras «domus ecclesiae», como en el caso de Lugo. Sin embargo, aún a finales del siglo IV la nueva religión se restringía únicamente a los núcleos urbanos, y zonas rurales más próximas ${ }^{42}$. Esto se explicaría por el escaso desarrollo en esta región de habituales elementos impulsores del cristianismo como son el mundo urbano y las grandes propiedades latifundistas.

El establecimiento de la primera organización territorial eclesiástica será un proceso largo y con diversas etapas. Durante el siglo V y la primera mitad del VI debemos hablar simplemente de la fijación del primer cuadro de diócesis de Gallaecia, entendidas como una teórica cobertura administrativa del territorio basada en una serie de iglesias episcopales. Esta red constituye una simple superposición de la organización administrativa romana en civitas y sus territorios. Probablemente su capacidad de control efectivo sobre el territorio sería aún muy limitada. De hecho las únicas evidencias arqueológicas en la actual Galicia que se pueden relacionar con dicha organización eclesiástica son las de las propias sedes de Lugo ${ }^{43}$, Ourense ${ }^{44}$ e Iria ${ }^{45}$.

Será en la segunda mitad del siglo VI, en conexión con el auge de las dinámicas políticas supralocales que ya hemos apuntado, cuando se produce la ampliación y verdadera consolidación de este cuadro episcopal. En el caso de la actual Galicia hay que hablar de cinco sedes: Lugo, Iria, Tui, Bretoña y Ourense $^{46}$. Cuatro de ellas, como en el resto del antiguo Imperio, se sitúan en ámbitos urbanos, o en su defecto, semiurbanos. La excepción es la sede de

41 DÍAZ MARTÍNEZ, 57 (Salamanca, 2004).

42 NÚÑEZ y CAVADA, 2001: 165.

43 NÚÑEZ RODRÍGUEZ, 1978: 130-134. CASTIÑEIRAS, 6 (A Coruña, 1990): 79.

44 NÚÑEZ RODRÍGUEZ, 1978.

45 SUÁREZ OTERO, 2004. PÉREZ LOSADA, 2002: 82-107.

46 TORRES RODRÍGUEZ, 1977. 
Bretoña ${ }^{47}$, que precisamente parece constituir una respuesta a la necesidad de organización eclesiástica de un área más extrema (el norte de Galicia), de manera similar a otras iniciativas eclesiásticas en periferias atlánticas como el suroeste de Gran Bretaña e Irlanda ${ }^{48}$.

Un mayor detalle de esta consolidación organizativa eclesiástica lo obtenemos hacia finales de ese mismo siglo gracias al extraordinario texto de la Divisio Theodomiri o Parroquial Suevo. Este documento, cuya autenticidad básica fue probada por P. David ${ }^{49}$, habría sido redactado entre el 570 y 580 y consiste en una lista de trece sedes episcopales, junto a sus «ecclesiae/ecclesias que in vicino sunt». Estas iglesias han sido calificadas como «parroquias», pero hay que tener en cuenta que el término parroquia no tenía en el siglo VI un significado unívoco, ya que podía aludir a la sede episcopal, $\mathrm{o}$ a una de las partes integrantes o simplemente a una iglesia rural ${ }^{50}$. En todo caso, según P. C. Díaz, se deben interpretar como iglesias no privadas, es decir, como aquellas pertenecientes a la sede episcopal ${ }^{51}$. No podemos entrar ahora en su estudio, sobre el que abundan los trabajos ${ }^{52}$, sino simplemente usarlo como contrapunto de la información arqueológica que poseemos.

Lo que refleja el Parroquial Suevo es que a finales del siglo VI los obispos eran ya capaces de mantener un cierto control efectivo fuera de los ámbitos y ejes centrales de la romanización que señalábamos previamente, en correspondencia, sin duda, con un creciente grado de control y organización político-administrativo del Reino Suevo ${ }^{53}$. Sin embargo, como es bien sabido, este control o intensidad de la capilarización territorial a través de las «ecclesiae» es distinto en cada zona. En general su densidad es mayor en el norte de Portugal y sur de Galicia que en la zona septentrional, donde además, abundarían las referencias territoriales y sociales de carácter indígena.

Todo esto parece reflejar una imagen de relativa fuerza de los poderes episcopales, capaces aún de controlar las interferencias de las aristocracias laicas, algo que se aprecia también en los textos de los concilios de la época ${ }^{54}$. En ese sentido podemos pensar que los obispos y jerarquías eclesiásticas de este período constituyen sin duda una importante parte de las élites supralocales que intuimos actuar en la Gallaecia tardorromana. Recordemos en este sentido que las «parroquias» del Parroquial Suevo serían también centros

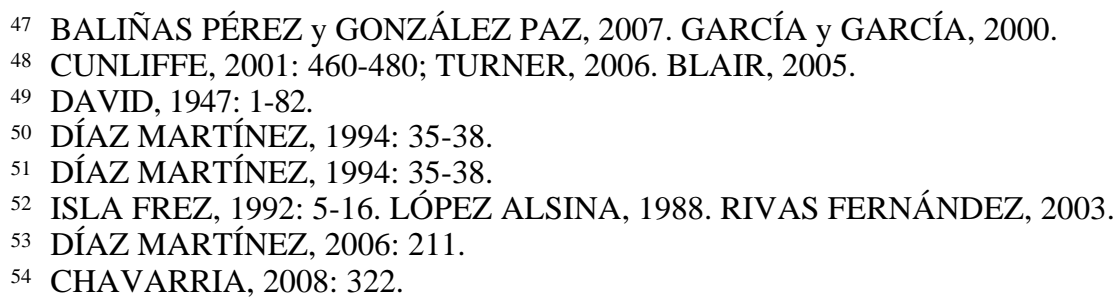


administrativos y económicos ${ }^{55}$ y los obispos no serían ajenos a su gestión. Se trata, por tanto, de élites que conocían bien el territorio y sus características que, en vez de superponer estructuras externas importadas, son capaces de adaptar y elaborar una organización diferente y específica.

\section{Los precedentes de las primeras iglesias: cristianización y áreas funera- rias en el mundo rural}

Según los datos arqueológicos disponibles, no podemos hablar de la existencia de iglesias como tales en la Galicia rural hasta probablemente la mitad del siglo $\mathrm{VI}^{56}$. Sin embargo, para entender su aparición hay que remontarse a la difusión previa del cristianismo en el mundo rural y su primera manifestación física en el paisaje: el mundo funerario. Se trata de un amplio, pero heterogéneo, conjunto de enterramientos ya claramente cristianos que aparecen mayoritariamente ligados a villae y establecimientos agrarios económicamente más importantes, $\mathrm{y}$, sobre todo, bien conectados con las principales vías de comunicación de la Galicia tardorromana, tanto terrestres, como marítimofluviales ${ }^{57}$. Esta distribución pone de relieve el carácter irradiado de la nueva religión desde los centros urbanos (figura 2) ${ }^{58}$.

$\mathrm{Al}$ analizar en conjunto las cronologías disponibles se observa que los enterramientos privilegiados son los primeros en aparecer. Ya desde fines del siglo IV, y sobre todo a lo largo del siglo $\mathrm{V}$, tenemos evidencias de ricos sarcófagos de mármol como el de Goiáns ${ }^{59}$ o Lourenzá60 ${ }^{6}$ crismones y mesas de altar como los de A Ermida de Quiroga ${ }^{61}$ o Bande ${ }^{62}$. Muchas de estas piezas, o al menos sus materiales, serían importados por vía marítima. Podemos pensar que algunos de ellos se combinaban con otros elementos decorativos o arquitectónicos, como capiteles y columnas, para crear un pequeño mausoleo, o monumento funerario, como el que podía existir en Santiago de Compostela, Temes ${ }^{63}$ o Amiadoso, así como pequeños oratorios como el de Ouvigo, que tiene ahora su fase inicial ${ }^{64}$. Se trata de un fenómeno y de una arquitectura similares a los de otras zonas del mundo tardorromano ${ }^{65}$.

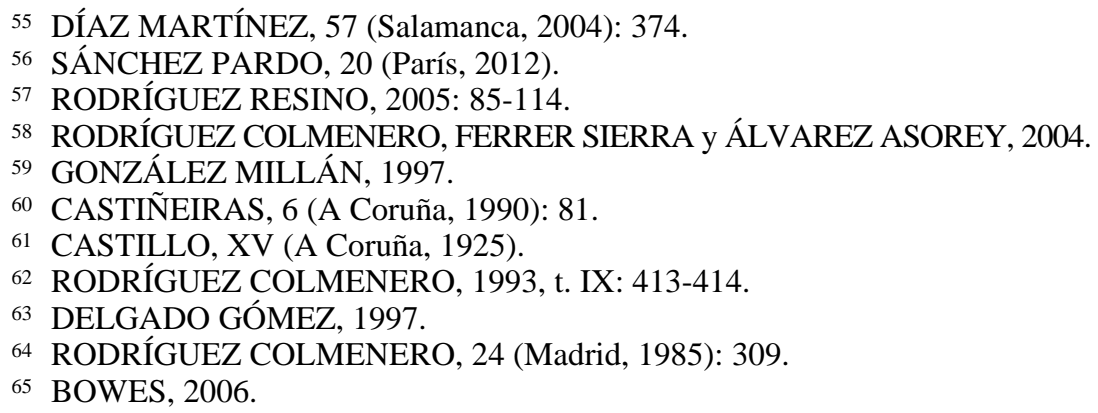



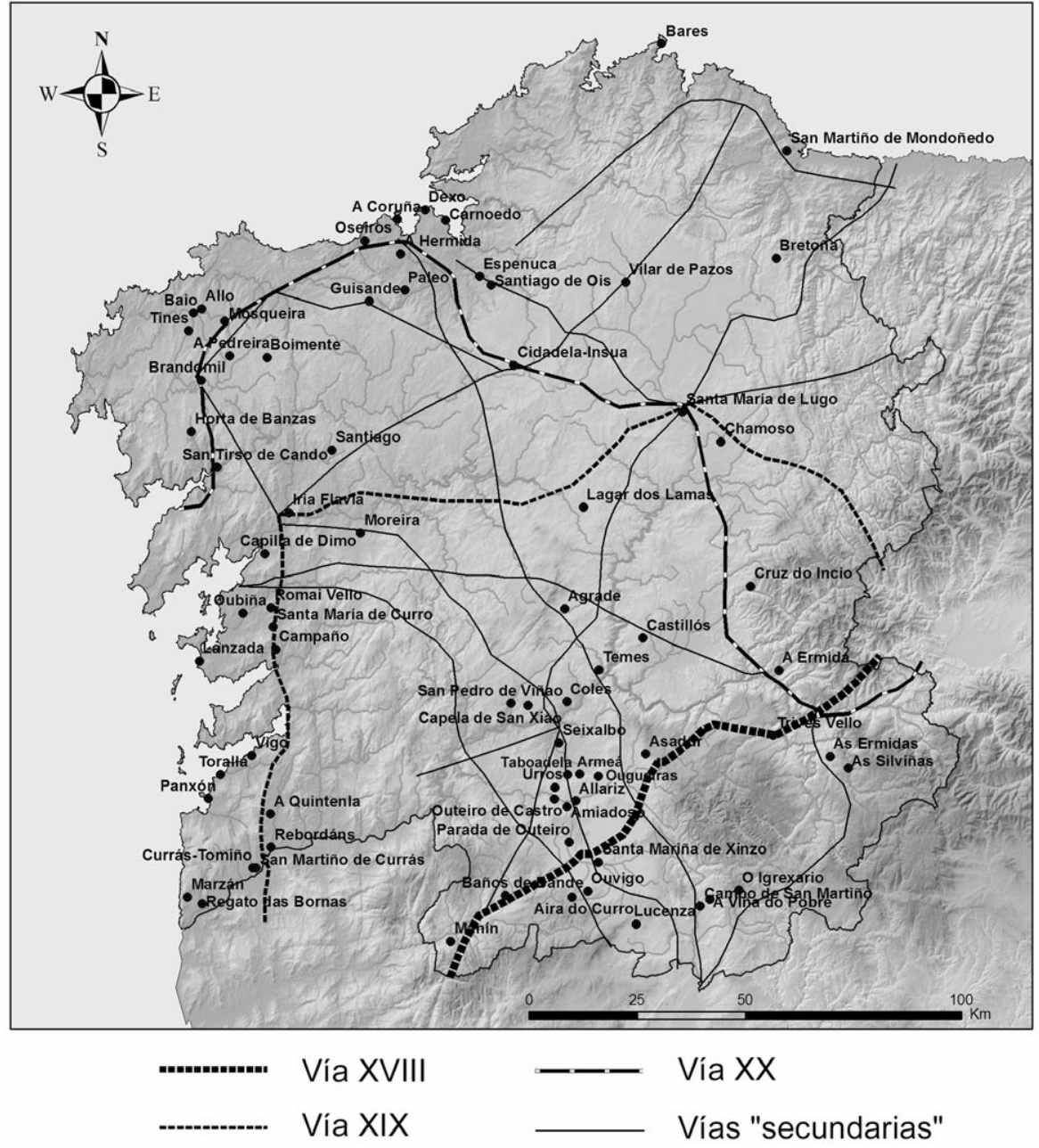

FIGURA 2: SELECCIÓN DE LAS PRINCIPALES NECRÓPOLIS TARDORROMANAS CONOCIDAS EN GALICIA (SS. IV-VII) Y SU RELACIÓN CON EL PROBABLE TRAZADO DE LAS PRINCIPALES VÍAS ROMANAS EN ESTA REGIÓN SEGÚN RODRÍGUEZ, FERRER Y ÁLVAREZ.

Nos interesa subrayar que esta inversión económica y de representación social que son dichos enterramientos privilegiados parece llevarse a cabo normalmente cuando las villae o establecimientos rurales todavía están en funcionamiento, entre los siglos V y VI. Como veremos, sólo tiempo después del abandono de esas villae (o al menos, de sus áreas de representación), muchos de estos pequeños oratorios y mausoleos serán convertidos en verdade- 
ras iglesias, sobre todo monásticas, entre los siglos VII-X. En ese sentido, como señalan Chavarría y Brogiolo, hay que desechar la tradicional idea de la construcción de templos en el mundo rural por las aristocracias y grandes propietarios durante la etapa de funcionamiento aun de sus villae y propiedades con la misión de cristianizar a los habitantes del entorno ${ }^{66}$. Las construcciones de estos sectores sociales corresponden más bien, como hemos indicado, a mausoleos, monumenta-martiria o, a veces, pequeños oratorios funerarios para uso privado dentro de sus propiedades rurales. En su creación, además de factores religiosos, influyen motivos de prestigio y representación social. Aunque esto tendrá probablemente un efecto impulsor de la cristianización rural, no constituye una red de organización ni encuadramiento eclesiástico.

En general, una vez abandonada la parte residencial de la villa, en los siglos VI-VII, aparecen enterramientos más humildes que se superponen a las antiguas estructuras de representación ${ }^{67}$ : Adro Vello, Currás-Tomiño, Bares, Panxón ${ }^{68}$, Rebordáns, San Martiño de Mondoñedo, Moraime, Tines... En todo caso este fenómeno suele ocurrir poco tiempo después de dicho abandono, a veces de manera inmediata, y también supondrá una importante base sobre la que se construirán, posteriormente, iglesias en estos lugares. Esto indica que existe una población viviendo y explotando el entorno inmediato. Como ya hemos señalado, podemos incluso pensar que en algunos casos asistimos no a un empobrecimiento general de los propietarios, sino más bien al enriquecimiento de algunos de ellos, que acaparan el resto de propiedades. De este modo, aunque se abandone la parte residencial, el sistema productivo y señorial podría seguir funcionando. Debemos, por tanto, ser cautos a la hora de juzgar estos procesos.

En todo caso, no todas las villas desarrollarán necrópolis cristianas en ellas, antes o después de su aparente abandono, ni son necesariamente aquellas más lujosas las que lo harán. Tampoco el grado de conectividad es un factor determinante en ello. La respuesta hay que buscarla, probablemente, en las distintas dinámicas económicas, sociopolíticas y de cristianización de cada comunidad. En todo caso, es cierto que hay áreas que parecen más activas, como la costa, la zona de Ribas de Sil o el entorno de la ciudad de Lugo.

66 BROGIOLO y CHAVARRÍA, 14 (Zagreb, 2008): 11.

67 CHAVARRIA ARNAU, 2007.

68 YZQUIERDO PERRÍN, 1993: 52-54. 


\section{Reflexiones sobre el contexto social y espacial de las primeras iglesias rurales en Galicia}

Desde mediados del siglo VI, y en conexión con el auge político y económico de unos pequeños pero importantes grupos de poder supralocal, comienzan a aparecer las primeras iglesias, como tales, en el ámbito rural galaico. Esta expansión será permitida e impulsada, además, por la consolidación desde finales del siglo VI de una liturgia hispánica específica que define y organiza la arquitectura y la distribución de los templos ${ }^{69}$.

Es difícil calibrar cuál sería la dimensión de esta primera expansión de iglesias rurales. Una posible aproximación a este panorama concreto de edificaciones eclesiásticas en la Gallaecia de finales del siglo VI podría venir de la mano del Parroquial Suevo. Aun teniendo en cuenta que este documento solo reflejaría las iglesias pertenecientes al poder episcopal, se cuentan un total de 132 iglesias para la Gallaecia sueva, de las que unas 30-50 aproximadamente corresponderían a la actual $\mathrm{Galicia}^{70}$. Aunque las diócesis de Braga y Portus Cale poseen muchas iglesias (30 y 25 respectivamente), la mayor densidad de las mismas, teniendo en cuenta la posible extensión de cada diócesis $^{71}$, estaría en Tui, con 17 iglesias en un área relativamente pequeña.

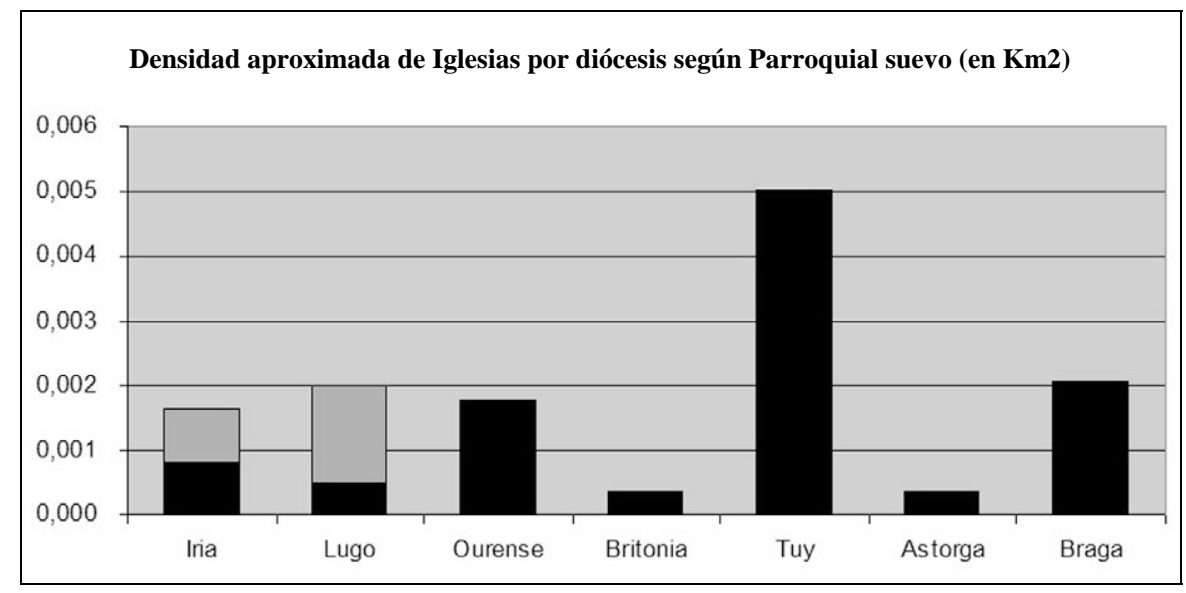

Figura 3: DENSIDAD COMPARADA DE IGLESIAS POR DIÓCESIS EN EL PARROQUIAL SUEVO (CA. 572 D.C.). EN EL CASO DE IRIA Y LUGO SE DISTINGUEN LOS RESULTADOS OBTENIDOS SI SE CONSIDERAN VÁLIDAS LAS INTERPOLACIONES AL TEXTO.

69 CHAVARRIA ARNAU, 2009, 15-90.

70 El número varía según consideremos válidas o no las interpolaciones añadidas a la diócesis de Iria y Lugo. F. López Alsina considera las de Iria como válidas LÓPEZ ALSINA, 1988: 155.

71 Partimos para ello de la reconstrucción de las diócesis del Parroquial Suevo que realiza RIVAS, 2003, lámina IX. 
Aun sin especular sobre el restante número de iglesias privadas que debían existir, la cantidad de edificaciones eclesiásticas en Gallaecia a fines del siglo VI según el Parroquial Suevo no es desdeñable. Y sobre todo, parece corresponder sin complejos de «indigenismo» a una tendencia común de fundación de iglesias y monasterios en gran parte del antiguo Imperio romano entre los siglos VI y VII. Se trata generalmente de pequeñas construcciones, poco propicias todavía para la reunión de un amplio número de fieles, pero que suponen ya una innegable implantación física de la Iglesia en el territorio ${ }^{72}$.

La creación de iglesias en este período parece estar relativamente bien controlada por los obispos, que debían autorizarlas y consagrarlas ${ }^{73}$. Los textos dejan ver que existía un importante componente de prestigio en estas primeras fundaciones de iglesias, pero también sabemos que solo las podrían hacer los individuos más poderosos ya que, además del coste económico de su construcción, estaba el de su adecuada dotación y mantenimiento. Estos fundadores debían, en teoría, contactar siempre con un obispo, que tomaba la tercera parte del patrimonio y rentas de la iglesia. De hecho, aún a mitad del siglo VII, en el concilio de Toledo del 647, se recrimina a los obispos de Gallaecia por abusar fiscalmente de sus iglesias ${ }^{74}$. Quizá podemos pensar que en este período los fundadores de iglesias están relacionados en mayor o menor medida con aristocracias residentes en el ámbito urbano, pero que poseen y controlan propiedades en el mundo rural, ya que, como veremos a continuación, todas estas iglesias están en el entorno de núcleos principales o en áreas bien conectadas con ellos a través de vías terrestres. No podemos incluso descartar que algunas de estas iglesias, en su relación o dependencia del mundo episcopal, supusieran ya una bisagra de articulación entre el mundo local y el estado suevo y, sobre todo, visigodo ${ }^{75}$. En todo caso no tenemos evidencias de pagos de diezmos u otro tipo de fiscalidad aplicadas en o desde estos templos, aunque sabemos que ya existían, de manera restringida, en algunas áreas ${ }^{76}$.

Como ya hemos adelantado, las iglesias rurales más tempranas constatadas se concentran prácticamente en las áreas y ejes centrales de la Galicia romana, donde aquellos poderes poseían o controlaban propiedades, generalmente ligadas al comercio y a las vías. En ese sentido es interesante señalar que no siempre se trata de las áreas más ricas en recursos, por ejemplo a nivel agrícola o minero, sino ante todo de las mejor conectadas. Podemos citar ejemplos como las iglesias de Córgomo ${ }^{77}$, Petín ${ }^{78}$, Xagoaza ${ }^{79}$, Saamasas ${ }^{80}$, San Roque

\footnotetext{
72 BROGIOLO y CHAVARRÍA, 2005: 127-143.

73 CHAVARRIA, 2008: 322.

74 WOOD, 2006: 13-16.

75 CASTELLANOS y MARTÍN VISO, 13 (Londres, 2005).

76 WOOD, 2006: 460.

77 RODRÍGUEZ COLMENERO, FERRER SIERRA y GARCÍA TATO, 2009: 87.
} 
de Lugo ${ }^{81}$ o Bóveda ${ }^{82}$. Esta distribución confirma que se trata de un proceso más exógeno que endógeno, es decir, que todavía no surge tanto de y en las comunidades locales como de poderes y dinámicas más amplias, supralocales.

Algunas de esas primeras iglesias, como Adro Vello, Goiáns, Vigo, Leis ${ }^{83}$ o Bares, se concentran en la costa gallega, en relación probablemente con el contexto de comercio a larga distancia que ya hemos comentado. Parece posible pensar que sus fundadores sean quienes promueven parte de dichos intercambios, ya que piezas decorativas de iglesias de este período, o al menos el mármol para hacerlas, como en Setecoros, llega a través de ese comercio ${ }^{84}$. Probablemente a través de esos intercambios llegarían también elementos de importación necesarios para el culto religioso: aceite, velas, vasos, platos, patenas... sin olvidar el comercio de reliquias, que aunque sería cuantitativamente puntual, tendría un enorme valor, prestigio e importancia en su contexto $^{85}$. Si, como propone C. Wickham ${ }^{86}$ consideramos la capacidad de intercambio a larga distancia como un indicador de la fortaleza de las élites, tendríamos que hablar en la Gallaecia del siglo VI y primera mitad del VII, de un mayor poder del habitualmente pensado para algunas de las mismas.

$\mathrm{Al}$ analizar la ubicación de estas primeras iglesias destaca su relación con estructuras romanas previas, especialmente villae o necrópolis. Este fenómeno, habitual en todo el occidente tardoantiguo, presenta todavía muchos problemas para su interpretación, pero parece probable que responda a una variedad de situaciones ${ }^{87}$. No debemos pensar que necesariamente haya relación entre la antigua propiedad romana, su dueño y el contexto de la nueva estructura eclesiástica. En todo caso, esta secuencia, al margen de la continuidad o no de los mismos propietarios, nos pone sobre la pista de un poder económico actuando en el mismo entorno tiempo después de la aparente desaparición de las antiguas élites tardorromanas, y probablemente poseyendo la propiedad o control de ese espacio, lo que explica que pueda fundar una iglesia en ellas. Esas nuevas iglesias heredarán la posición espacial, generalmente estratégica, que aquellas propiedades poseían dentro de los ejes centrales de comunicación y dinamismo de la Galicia tardorromana que sí seguirán prevaleciendo.

78 RODRÍGUEZ COLMENERO, FERRER SIERRA y GARCÍA TATO: 79.

79 RODRÍGUEZ COLMENERO, FERRER SIERRA y GARCÍA TATO: 80-86.

80 YZQUIERDO PERRÍN, 1993: 56-57.

81 YZQUIERDO PERRÍN: 60-63.

82 BLANCO-ROTEA, BENAVIDES GARCÍA, SANJURJO SÁNCHEZ y FERNÁNDEZ MOSQUERA,6 (Madrid, 2009).

83 SUÁREZ OTERO, 2004: 91.

84 YZQUIERDO PERRÍN, 1993: 57-59.

${ }^{85}$ LE JAN, 2001: 244.

86 WICKHAM, 2005: 707, 819.

87 CHAVARRIA ARNAU, 2007: 157-159.

Hispania, 2013, vol. LXXIII, nº. 243, enero-abril, págs. 11-50, ISSN: 0018-2141, e-ISSN: 1988-8368, doi: 10.3989/hispania.2013.002 
Una propuesta explicativa podría ser, como señalábamos antes, que sea la Iglesia la que había acaparado propiedades y disponga ahora de la capacidad para fundar dichas estructuras en ellas.

Más allá de esta primera consideración física está el nivel del significado o intención que esta reutilización pueda tener. Algunos autores consideran esta coincidencia espacial como una estrategia legitimadora, o como un reuso simbólico del pasado romano ${ }^{88}$, que además estaría controlado dado precisamente su potencial ideológico como «principio maleable para la reorientación del paisaje cultural» ${ }^{89}$. Otros hablan principalmente de aprovechamiento de

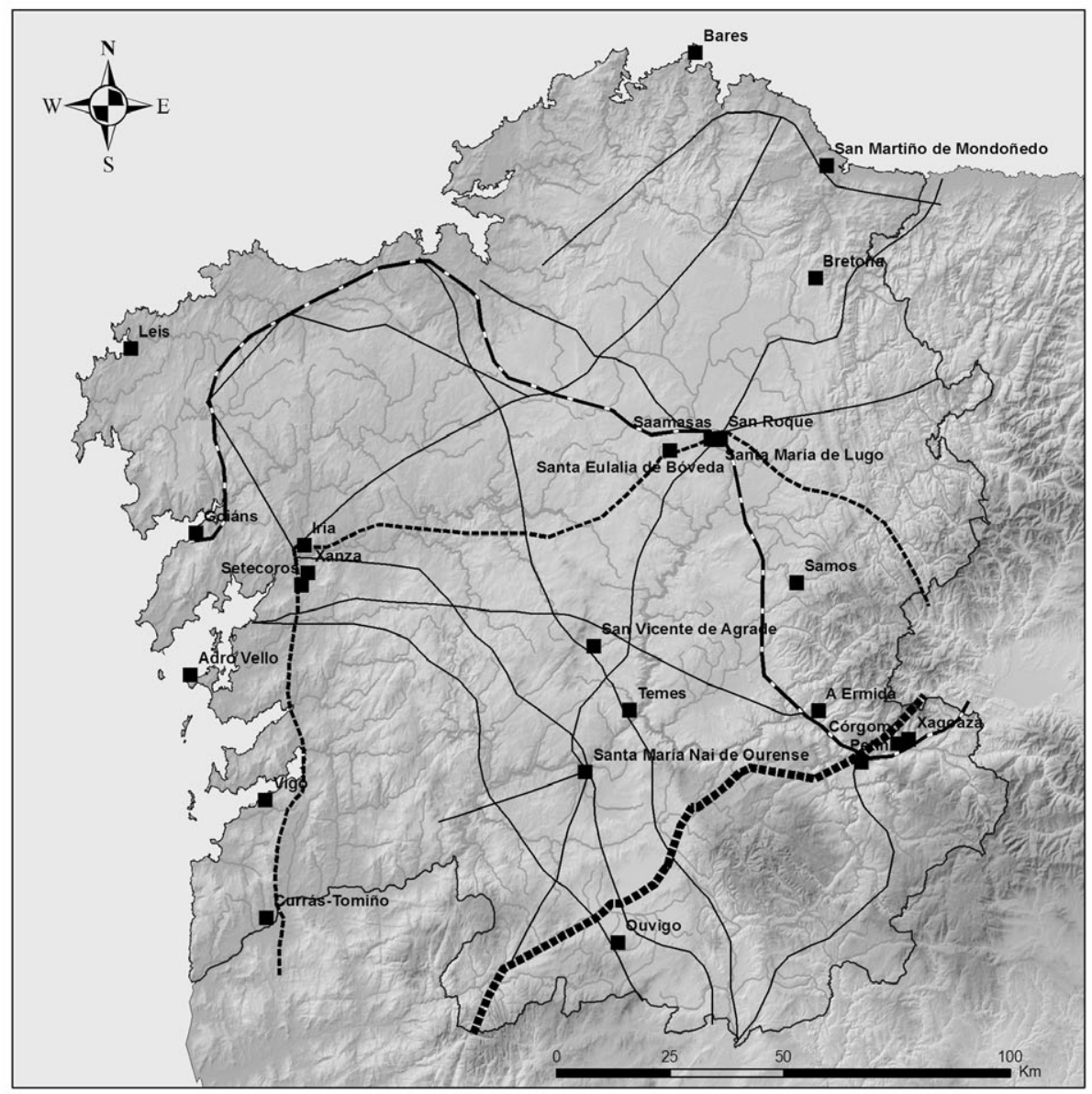

FigURA 4: EVIDENCIAS MATERIALES DE POSIBLES IGLESIAS EN GALICIA ANTES DEL 650 D.C.

88 BELL, 2005.

89 EFFROS, 2001: 118. 
materiales, sin que esto implique necesariamente pobreza ${ }^{90}$. En nuestra opinión existen distintas respuestas según cada contexto. No todas las necrópolis de los siglos V-VI desarrollarán una iglesia sobre ellas, y, sobre todo, no todas lo hacen en este período (siglos VI-VII), sino que se trata de un proceso que se extenderá hasta el siglo X, por lo menos, a veces con un largo lapso de abandono en medio ${ }^{91}$. De hecho, una de las posibles razones para la creación de una iglesia en esos contextos es la identificación de un antiguo mausoleo y su consideración como un santo o mártir, es decir, una «inventio» de reliquias $^{92}$. Se trata de un fenómeno habitual en toda la Alta Edad Media, y que en Galicia ocurrirá no solo en Santiago a inicios del siglo IX, sino probablemente también en el caso de Temes o Quiroga. Todo esto nos lleva, por tanto a la necesidad de distinguir entre la superposición espacial de iglesias y antiguos establecimientos romanos en la Galicia tardoantigua (siglos V-VIII), poco tiempo después del abandono de la villa, del reuso de antiguos lugares romanos en los siglos IX-XI. El primero parece estar más ligado a razones económicas de propiedad, mientras que el segundo podría relacionarse más con motivos simbólicos o legitimadores, especialmente en relación con el proceso «repoblador».

Por último, y como excepción a esta mayoría de iglesias ligadas a contextos que podríamos denominar «centrales», hay que señalar que aparecen también ahora algunos primeros intentos controlados por los obispos de creación de iglesias en ámbitos más periféricos, como es la aparición de las sedes monásticas de Bretoña y Dumio, y la posible creación en este período del monasterio de Samos. Todavía son muy puntuales, pero su importancia será grande en el período siguiente, a través de las iniciativas privadas. A pesar de su fama, no tenemos datos fiables sobre la existencia en este período de eremitorios rupestres ${ }^{93}$.

\section{LA EXPANSIÓN DEL MONACATO Y LAS IGLESIAS PROPIAS EN UN CONTEXTO DE FRAGMENTACIÓN E INTENSIFICACIÓN LOCAL DE LOS PODERES (CA. 650- 800 D.C.)}

\section{El «largo siglo VIII» en Galicia: de la fragmentación del mundo tardoan- tiguo a los nuevos espacios de poder supralocal}

En torno al segundo tercio del siglo VII, el panorama arqueológico precedente parece cambiar. El ambiente de continuidad de contextos culturales

\footnotetext{
90 BRENK, 1987. CHAVARRIA ARNAU, 2009: 108.

91 FIXOT, 1989: 18. BELL, 2005: 131.

92 EFFROS, 2001.

93 FREIRE, 1998: 191-275.
} 
tardorromanos previo se agota. Los materiales importados y las evidencias de contactos marítimos no sobrepasan la mitad del siglo VII. La mayor parte de los aglomerados secundarios y principales establecimientos tipo villa ya se han abandonado definitivamente. En cuanto al resto de asentamientos rurales tardorromanos, aunque en general parecen mantener una estabilidad de ocupación, sí se observan una serie de transformaciones o reajustes entre finales del siglo VI y/o a lo largo del siglo VII ${ }^{94}$. Podríamos interpretarlos como una fijación definitiva de la estructura de hábitat, quizá un cambio de granjas a verdaderas comunidades aldeanas ${ }^{95}$. En ese sentido apuntan los análisis de espacios agrarios gallegos, que muestran un proceso de estabilización e intensificación de la producción en este momento, principalmente a través de la construcción de terrazas agrarias ${ }^{96}$. Igualmente en esta época parecen aumentar las diferencias y jerarquizaciones en las formas de enterramiento con la presencia de sarcófagos monumentales que denotan alto estatus social (como los de estola y doble estola).

Los textos no nos dan demasiada información para este período en Galicia, pero, en términos generales, parece producirse una desaceleración de los elementos de control supralocal previos, por ejemplo a nivel administrativo ${ }^{97}$. Los últimos años del Reino Visigodo, caracterizados por la inestabilidad política y social, tampoco parecen conllevar en Galicia ningún especial dinamismo de organización política. La invasión musulmana acelerará considerablemente esta desintegración de estructuras políticas superiores, aunque su impacto en la vida local de esta parte de la península ibérica fue muy escaso ${ }^{98}$.

En general estos indicios parecen reflejar la transición social que, con diferentes ritmos e intensidades en cada zona, señala el definitivo fin del mundo tardorromano, caracterizado todavía por un cierto dinamismo político-económico supralocal, y el nacimiento del altomedieval, basado en comunidades aldeanas y poderes locales. Se trata de un proceso global en la antigua Europa romana ${ }^{99}$. La clave de la transición en cada zona es el grado de desestructuración con el fin del mundo tardorromano, que conllevará la posibilidad de crecimiento para nuevas élites, la aparición de «espacios de competición», que en muchas áreas europeas se refleja especialmente en las formas de enterramiento ${ }^{100}$.

En el caso de Galicia, como hemos podido ver, esta transición parece producirse de manera más suave y tardía, con un eje en torno al siglo VII ${ }^{101}$, de

94 LÓPEZ QUIROGA, 2004: 292-294.

95 SÁNCHEZ PARDO, XXXVII (Siena, 2010): 273-275. ISLA FREZ, 1992: 10.

96 BALLESTEROS ARIAS, 2010.

97 DÍAZ MARTÍNEZ, 57 (Salamanca, 2004): 367-375, 2006: 201-215.

98 PALLARES y PORTELA, 1997.

99 WICKHAM, 2005: 434-436

${ }^{100}$ HÄRKE, 2001. HALSALL, 1995.

${ }^{101}$ LÓPEZ QUIROGA, 2004, 290-296. 
manera similar a otras zonas del occidente atlántico tardoantiguo ${ }^{102}$. Se plasmaría ante todo en una reestructuración territorial y el fortalecimiento de la actuación de los poderes a escala local tras el debilitamiento de las aristocracias mayores. Aunque aún queda mucho por estudiar, no parece tratarse de una ruptura, sino más bien de un reajuste sobre el anterior paisaje tardorromano, con una evolución desde un poblamiento en grupos familiares a verdaderas comunidades aldeanas ${ }^{103}$. Se trata en definitiva de una tendencia a la fragmentación sociopolítica ${ }^{104}$, pero sin que esto implique necesariamente debilidad, sino que parece constatarse cierta vitalidad, riqueza y articulación dentro de esa escala local ${ }^{105}$. Esta concentración de los poderes en el ámbito local parece ser una de las bases que explicarán más tarde, a inicios del siglo IX, el progresivo ascenso de un grupo de grandes propietarios reflejado en la documentación escrita.

Por tanto, desde un punto de vista más amplio y comparativo, podemos encuadrar este proceso dentro del inicio de las llamadas transformaciones del «largo siglo VIII» que se constatan, con importantes matices, a lo largo de toda Europa Occidental entre finales del siglo VII e inicios del siglo IX y llevarán al nacimiento de los primeros reinos nacionales y el fortalecimiento de la presión sobre las comunidades, con sus correspondientes reflejos en el paisaje ${ }^{106}$. Se trata, obviamente, de procesos complejos que no se pueden reducir a explicaciones únicas ${ }^{107}$. En todo caso, nos interesa señalar que el noroeste peninsular no es una excepción ni representa la «excepcionalidad hispánica». La clave de lectura no es tanto la ruptura por la invasión islámica como la posterior organización y avance de una nueva estructura política supralocal, el Reino de Asturias, en consonancia con el ambiente político europeo. También hay que entender así la creciente presión de los omeyas en Al-Andalus en ese

102 TURNER, 2006.

103 SÁNCHEZ PARDO, XXXVII (Siena, 2010); SÁNCHEZ PARDO (Londres, en prensa)

104 ESCALONA MONGE, 2006.

105 CASTELLANOS y MARTÍN VISO, 13 (Londres, 2005).

106 WICKHAM, 2000: 191.

${ }^{107} \mathrm{C}$. Wickham hace especial énfasis en las fuertes diferencias regionales que caracterizan las distintas áreas económicas de Europa, tras el proceso de fragmentación y «localización» que, con diferentes ritmos e intensidades se desarrolla desde el siglo VI. WICKHAM, 2000. Teniendo en cuenta esta base, no pretendemos aquí «encajar» el caso de Galicia en un modelo (que en este caso debería ser el del «Mediterráneo Occidental») sino más bien sondear su coherencia dentro de unas tendencias generales. Como hemos tratado de señalar, el panorama gallego muestra un mayor mantenimiento de las estructuras tardorromanas, y una más suave y más tardía crisis del siglo VI, desembocando a su vez en un proceso más tardío y prolongado, pero no terminal, de fragmentación y «aislamiento» en este «largo siglo VIII». Sobre este especial dinamismo de Galicia dentro de su "periferia» y en el contexto del norte peninsular véase: BALIÑAS PÉREZ, 2002. 
mismo período, que llevará a protestas de las antiguas familias visigodas por el mantenimiento de su estatus ${ }^{108}$.

\section{Sobre el impacto de la invasión árabe en la organización eclesiástica ga- laica}

La organización eclesiástica galaica parece mantenerse relativamente estable tras los ajustes de finales del siglo VI y hasta la conquista árabe de la península ibérica. En este período, los obispos de Gallaecia acuden con normalidad y regularidad a los concilios de la Iglesia del Reino Visigodo, aunque se constata una progresiva pérdida de su control efectivo sobre las iglesias locales ${ }^{109}$. Sin embargo, la invasión árabe del año 711 supondrá la práctica desarticulación del nivel superior de dicha organización, con el abandono de la mayor parte de las sedes episcopales de Galicia. Su proceso de reorganización posterior será largo e implicará una serie de cambios (obispos refugiados, desaparición de la sede de Bretoña, reajustes territoriales...).

No obstante, esta desarticulación organizativa no supondrá ninguna ruptura en la vida eclesiástica local en el siglo VIII ${ }^{110}$. No tenemos ninguna evidencia arqueológica todavía de un abandono definitivo de un edificio eclesiástico en Galicia a partir del siglo VIII, y cuando las hay, como Ouvigo o Adro Vello, son muy posteriores. Esto no excluiría un posible abandono temporal. Sin embargo, en toda Galicia se aprecia el mantenimiento o recuerdo de muchas titulaciones de época visigoda en los siglos siguientes. Además, la continuidad del estilo artístico de las iglesias hispanovisigodas durante los siglos VIII, IX y parte del $\mathrm{X}$ también apunta a una pervivencia de aquel sustrato previo ${ }^{111}$. E igualmente, la continuidad de la tradición religiosa de carácter monástico y familiar de la iglesia galaica del siglo VII durante los siglos siguientes, hasta el XI, habla en contra de una cesura112.

Encontramos más matices a esta idea general de continuidad en cada zona de Galicia. En el territorio de la sede de Iria no existió ninguna ruptura, ni siquiera a escala de organización diocesana, lo que incluye casi la mitad occidental de la actual Galicia113. En el caso de Lugo, aunque hubo un temporal abandono de la sede, sabemos que a mitad del siglo VIII, es decir, menos de 35 años después de la conquista, el poder Astur está incorporando iglesias a su órbita en

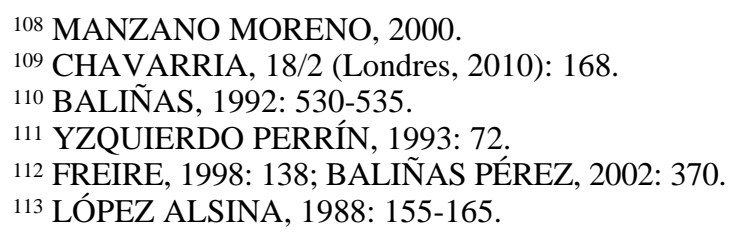


el entorno de Lugo ${ }^{114}$. En este período tan breve no puede haber dado tiempo a que desapareciese la tradición cristiana del territorio. Tampoco parece factible que se haya producido una destrucción sistemática, probablemente ni siquiera parcial, de las iglesias rurales existentes por parte del breve gobierno musulmán, ya que ésta no se produjo ni siquiera en otras zonas del sur peninsular ${ }^{115}$. En la mitad sur de Galicia la desarticulación fue más profunda y quizá pudieron abandonarse ciertos templos ligados a poderes supralocales. Sin embargo, no tenemos constancia de ningún proceso de «reevangelización» durante los siglos IX-X, cuando esta mitad meridional se incorpora al Reino Astur.

Por tanto, aunque se produce una desarticulación de las estructuras superiores de organización eclesiástica en la mitad sur, hay que desechar las visiones de destrucción o desaparición del tejido eclesiástico local. Esta visión puede tener mucho que ver con discursos legitimadores posteriores elaborados por la monarquía astur-leonesa en los siglos IX-X ${ }^{116}$ en su incorporación de nuevos territorios y espacios de poder, relacionados con la idea del «desierto» y «despoblación». El proceso que realmente nos interesa es el de la pérdida de capacidad de control de las iglesias locales por los obispos galaicos y su relación con la fragmentación política y fortalecimiento de poderes locales. En todo caso, los obispos no desaparecen durante este período, sino que simplemente se comportarán como otros propietarios, incluso con manifestaciones de «propietariedad» de iglesias ${ }^{117}$.

\section{El auge de las fundaciones privadas}

Las evidencias materiales y la elevada cantidad de iglesias documentadas a inicios del período posterior, ya en el siglo $\mathrm{IX}^{118}$, hacen pensar en un crecimiento sostenido del número de edificaciones eclesiásticas desde mitad del siglo VII y durante el siglo VIII, una vez que descartamos la idea de un corte o ruptura en dicho proceso a escala local por la invasión árabe. Sin embargo, es arriesgado tratar de ofrecer un listado preciso de las fundaciones de este período. En todo caso, se tiende a usar como criterio de distinción a nivel artístico una menor calidad y pérdida de naturalismo en las elaboraciones artísticas «hispanovisigodas», sobre todo capiteles, a partir de mitad del siglo VII. Siguiendo este indicador, y algunos otros datos del contexto territorial y toponímico, podemos pensar que a esta segunda época corresponden, entre

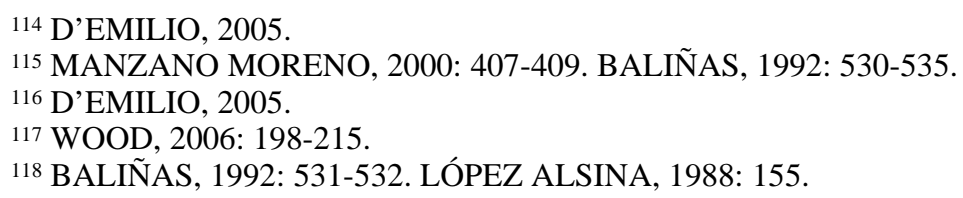


otros, edificios como Toques ${ }^{119}$, Carcacía ${ }^{120}$, Mártores ${ }^{121}$, Mosteiro ${ }^{122}$, Ferreira de Pallares ${ }^{123}$, Mens ${ }^{124}$, Vilaronte ${ }^{125}$ o las iglesias que existieron en Panxón y Cidadela ${ }^{126}$. También parece probable que hubiese frecuentes reconstrucciones de edificios previos, como sucedería en la iglesia de Setecoros ${ }^{127}$.

Según la imagen que transmiten los concilios hispanos a partir de este momento, se trataría sobre todo de fundaciones privadas, que escapan cada vez más al control episcopal ${ }^{128}$. Este incremento de iglesias privadas se puede relacionar con las transformaciones señaladas previamente y que llevan a una fragmentación política y al fortalecimiento de los poderes a escala local, fuera por tanto del control episcopal. Se trata de un proceso largo y que irá en aumento hasta al menos inicios del siglo IX. De hecho, aún en la mitad del siglo IX, según el llamado documento de Tructino ${ }^{129}$, vemos cómo las iglesias controladas por el obispo de Iria se ceñían únicamente a la costa, a los principales valles fluviales y al paso de la vía romana XX.

Las razones para la creación de una institución eclesiástica por parte de miembros de las élites locales son las mismas que señalábamos en el período precedente, ligadas a motivaciones de recompensa espiritual, creación de un lugar de cementerio propio, prestigio y representación social, o la propia idea del lugar sagrado, con poderes especiales ${ }^{130}$. Pero cada vez más intervendrán en este período factores económicos, de atracción de donaciones y limosnas y, sobre todo, de mantenimiento de la integridad del patrimonio familiar, algo clave en la consolidación de ciertos grupos de poder, como veremos en el caso de los monasterios.

En cuanto a los contextos arqueológicos y espaciales de fundación de estas nuevas edificaciones en Galicia, observamos dos tendencias: una que continúa formas previas, y otra que supone nuevos espacios y sustratos de «eclesificación». La primera se desarrolla principalmente en las zonas centrales, más romanizadas y comunicadas, estableciéndose generalmente sobre necrópolis y contextos funerarios tardorromanos previos, al igual que en el período precedente. Este es el caso quizá de Panxón, Moraime, Cidadela o Proendos.

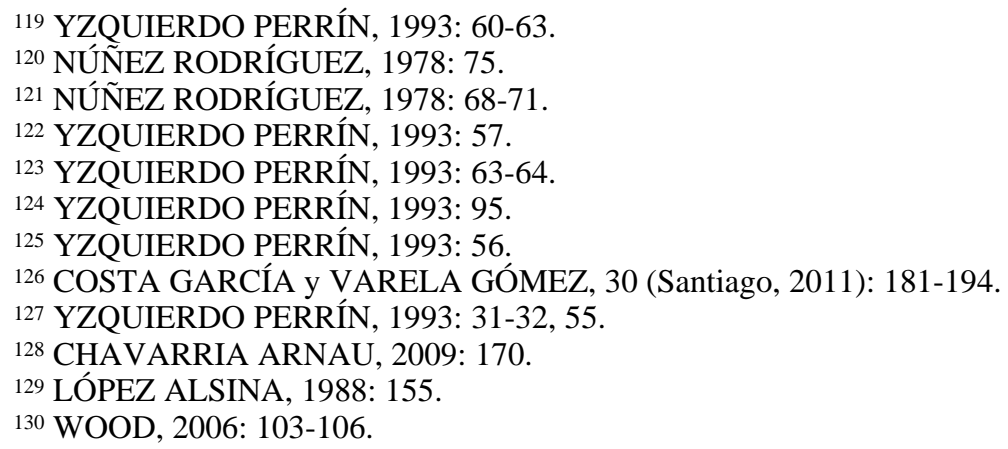




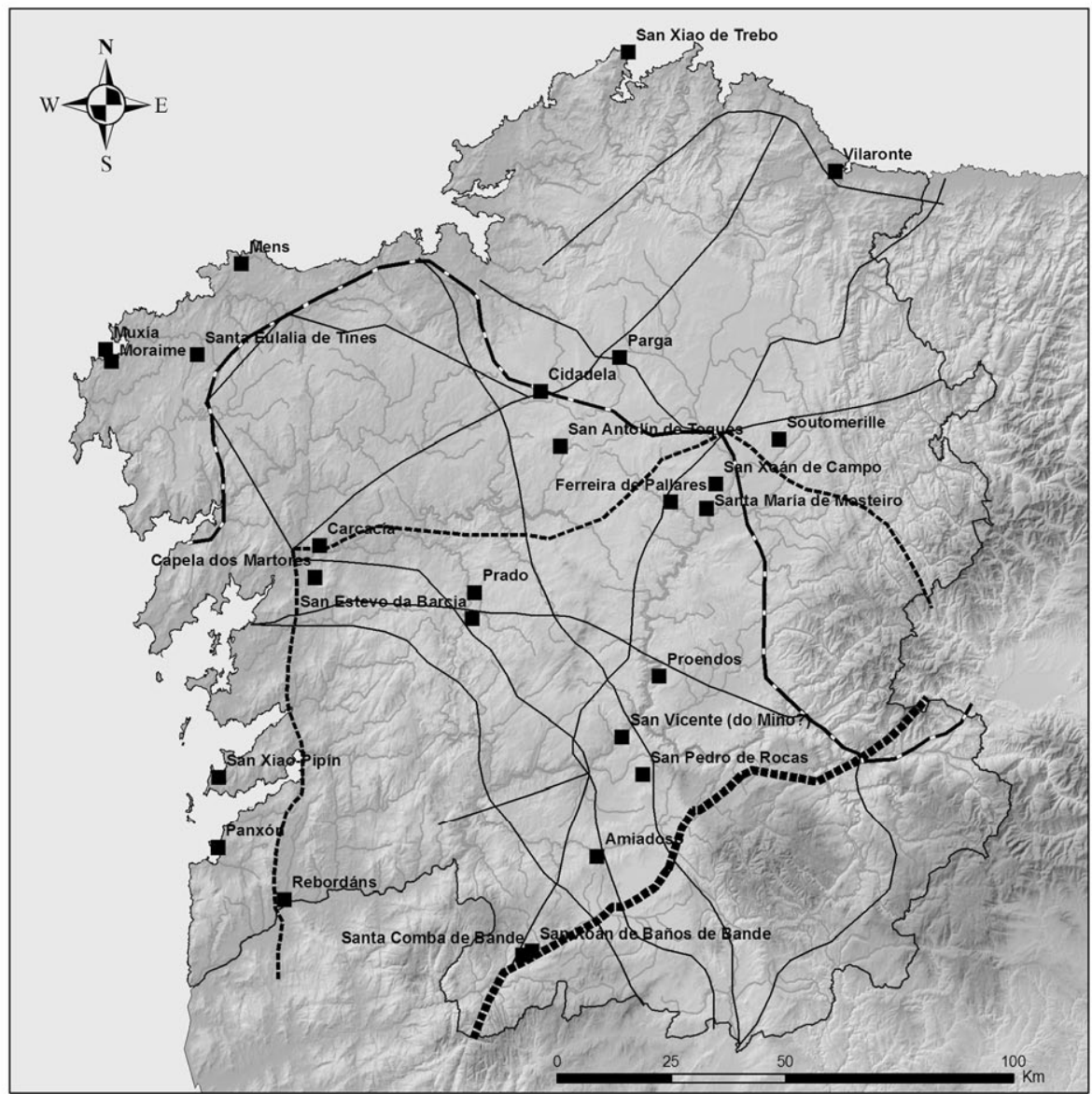

Figura 5: EVIDENCIAS MATERIALES DE POSIBLES IGLESIAS EN GALICIA ENTRE EL 650 D.C. Y EL 800 D.C.

Pero por otro lado, aparecen numerosas fundaciones en áreas más periféricas de Galicia, como Toques, San Xoán de Campo, Mosteiro o Prado. Se trata de una importante novedad, ya que estas zonas apenas habrían experimentado presencia eclesiástica en los siglos previos: áreas de interior más alejadas de las vías principales, zonas de montaña, y en general, gran parte de la mitad norte de Galicia. En este sentido, no tenemos generalmente datos de estructuras ni ocupaciones previas a la fundación de estas edificaciones en todas estas áreas. Por esta razón es más difícil postular cuales serían los motivos que llevan a la creación de una edificación eclesiástica en un lugar concreto en estas áreas. En todo caso, a la luz de otras zonas europeas, parece sin duda que los 
motivos de propiedad de los terrenos son decisivos, por encima incluso de aquellos simbólicos.

\section{El papel de los monasterios en un contexto de transformaciones}

En este proceso de expansión de edificaciones religiosas en los siglos VIIVIII juegan un papel fundamental los monasterios, como vemos en las biografías de San Fructuoso y Valerio del Bierzo. En ellas se observa el gran éxito y difusión de las fundaciones monásticas por toda Gallaecia desde mitad del siglo VII, mientras que las iglesias episcopales tendrían más problemas. P. Díaz cree que esto se debe a que los monasterios ofrecen un sistema de protección de vida tradicional dentro del panorama de cambio (que aquí ampliamos también al paisaje), y a que además eran autosuficientes, a diferencia de las iglesias 131 . En todo caso, el auge de las fundaciones de monasterios desde el siglo VII parece constatarse en otras zonas de Europa Occidental, como la Inglaterra anglosajona ${ }^{132}$ o en los reinos francos, donde en este siglo se pasó de 215 a 550 monasterios ${ }^{133}$.

Pero, como es sabido, en el noroeste peninsular se configurará un mundo monástico con un carácter muy específico y peculiar. Concretamente se pueden distinguir dos tipos de monasterios, como se observa en los destinatarios de las dos famosas reglas monásticas de la Gallaecia de este período: la regla que San Fructuoso compuso para su monasterio de Cómpludo a mitad del siglo VII y la Regula Communis, escrita probablemente por el mismo autor en torno al 660. Se trata de normas para ámbitos monásticos muy diversos. La estricta regla de San Fructuoso se adoptaría, creemos, en las fundaciones monásticas más importantes, por parte de élites más poderosas. Pero podemos pensar que el resto, seguramente la mayoría, nacieron de iniciativas locales, y para ellas que se escribirá la Regula Communis. Según P. Díaz se trataba de «monasterios vecinales», un tipo de monacato muy extendido basado en el pacto monástico, y que agrupa a pequeñas comunidades lideradas por un patrón local, normalmente un propietario con su familia y siervos ${ }^{134}$. Esta peculiar forma de organización constituiría un auténtico instrumento de aculturación y conciliación de tradiciones indígenas con las influencias externas del cristianismo hispanovisigodo, y ayudaría a la adaptación social en el contexto de transformaciones del siglo VII ${ }^{135}$.

131 DÍAZ, 2001: 337.

132 BLAIR, 2005.

133 LEBECQ, 2000: 123; LE JAN, 2001: 243-245.

134 DÍAZ, VII (Murcia, 1990).

135 DÍAZ, 2001: 329-359. 
Así, la mayor parte de nuestras evidencias parecen corresponder a monasterios. Los indicios históricos, la configuración del espacio arqueológico o la toponimia nos indican que probablemente casos como Samos, Ferreira de Pallares, Mosteiro, Bande, Moraime, Toques o las estructuras de Cidadela constituían monasterios en esta etapa. Se trata en su mayoría de fundaciones en áreas de la mitad norte de Galicia, con menor presencia eclesiástica hasta ese momento. En todo caso, a la luz de los indicadores cronológicos, podemos pensar que estos monasterios aparecieron antes, en la segunda mitad del siglo VII, en los puntos mejor comunicados, y solo en el siglo VIII (y posteriormente) se fueron extendiendo al resto del territorio.

Pero sobre todo, en relación con los planteamientos de este trabajo, consideramos que estas pequeñas fundaciones monásticas jugarían un papel esencial en el amplio proceso de estructuración del paisaje gallego de este período, al que nos hemos referido anteriormente, y su reflejo sociopolítico, que es la tendencia a la fragmentación política, el fortalecimiento de los poderes locales y el posterior y lento crecimiento de alguno de ellos. Los monasterios constituirán una auténtica vía de entrada de nuevas formas de organización política y de la propiedad en estas áreas periféricas gallegas. Si se hace necesario escribir una regla para todos estos monasterios es porque era un fenómeno en ebullición, reciente en el tiempo, y que no tenía un precedente para organizarse. Podemos interpretar también que esta organización supuso una oportunidad para la competición por esferas de poder antes inexistentes, o ya copadas, en estas zonas e incluso una mayor evangelización de ciertas áreas de montaña.

Comenzando por el plano físico, es posible pensar en alguna relación entre el establecimiento de estas pequeñas comunidades monásticas y la estabilización o reajuste de la red de poblamiento en este período. Si hubo una transformación de una red de granjas y pequeñas aldeas a verdaderas comunidades aldeanas en este período ${ }^{136}$, como parece constatado en otras zonas de la península ibérica y de Europa ${ }^{137}$, que implicó una intensificación de la producción, como indican los estudios agrarios, y el crecimiento de élites locales que se aprecia en las distinciones funerarias, parece coherente pensar en la aparición de monasterios como reflejo de ese cambio socioeconómico y garantes de la estabilidad y prosperidad de algún grupo familiar de la aldea. Como se indica en la Regula Commnunis, los monasterios permiten una primera coaportación y concentración de distintas propiedades de los profesos, lo que refleja un contexto de cambio y necesidad de estabilizarlo ${ }^{138}$. En ese sentido, la iglesia o monasterio representa una fijación de élites y comunidades al es-

136 SÁNCHEZ PARDO, XXXVII (Siena, 2010).

${ }^{137}$ FRANCOVICH y HODGES, 2003. HAMEROW, 2002. QUIRÓS CASTILLO, 2009.

138 DÍAZ, 2001: 351. 
pacio local, un elemento de anclaje del poblamiento, organización y desarrollo agrícola, aunque todavía a pequeña escala ${ }^{139}$.

Esto nos lleva al ámbito de una cierta estratificación socioeconómica a nivel local. Probablemente, a la altura de finales del siglo VII y durante el VIII, no debamos sobrevalorarla ni confundirla con los posteriores grupos aristocráticos. Pero sí parece que aquí se encuentra la base de esos futuros grupos. Y desde luego la elección y creación de un monasterio en este período puede ser clave para su consolidación. Se trata de nuevo de una tendencia común europea. En el norte de Francia, en los siglos VII-VIII la fundación de monasterios o conventos suponen auténticas estrategias de consolidación de grupos familiares en escenarios de competición y violencia regulada entre ellos. Como señala R. Le Jan, los monasterios o conventos de esta época eran auténticos lugares de poder ya que, además de su importancia para asentar el poder de un grupo, permitían construir redes de clientelas e intervenir directamente en juegos de herencias y de circulación de tierras ${ }^{140}$. Es interesante ver que esas pugnas de poder dependen mucho de la adecuada elección inicial del emplazamiento del monasterio. La conectividad es sin duda uno de esos factores principales ${ }^{141}$. Incluso en el caso de Irlanda, habitualmente considerada un espacio periférico, se puede entrever un papel crucial de los centros monásticos y su población adyacente (monastics towns) ya desde los siglos VII-VIII en el posterior crecimiento económico ${ }^{142}$. Creemos que en Galicia no tenemos un panorama muy diferente al de estos casos de la Europa atlántica.

Por supuesto, no todos los monasterios triunfarán a largo o medio plazo. Muchos se arruinarán, como se aprecia en documentos de los siglos IX-X, otros serán absorbidos por monasterios mayores... En todo caso sí podemos pensar que parte de las aristocracias que vemos surgir en el siglo IX podrían esconder su primera base patrimonial y de poder social, en este período, en la creación de un pequeño monasterio local. La importancia de estos centros locales explica el afán de la monarquía Astur en el siglo IX por controlarlos (a menudo legitimándose con restauraciones) y hacer de ellos la base de integración de nuevos espacios en el avance de la nueva formación política ${ }^{143}$. Aquí se encuentra una estrategia de investigación muy prometedora en el futuro ${ }^{144}$.

En todo caso, debemos nuevamente distinguir según cada zona. Por un lado, se crearían monasterios en las antiguas zonas «centrales», relacionados sobre todo con las vías principales de comunicación, como, por ejemplo, Bande, Ti-

139 ISLA FREZ, 14, (Jaén, 2007): 16.

${ }^{140}$ LE JAN, 2001: 244.

${ }^{141}$ LEBECQ, 2000: 128. BLAIR, 2005: 194.

142 DAVIES, 2009. Ó CARRAGAÍN, 2010: 9-15.

143 D’EMILIO, 2005.

${ }^{144}$ KIRCHNER, 28 (Salamanca, 2010): 250. 
nes o Cidadela. Tampoco hay que olvidar las iglesias creadas por obispos, que seguirán realizándose, aunque más bien desde una concepción de obispopropietario, como pueden ser muchas de las que se citan posteriormente en el documento de Tructino en la sede de Iria, como Carcacía. Por otro lado estarían las fundaciones en áreas periféricas, inauguradas quizá con la actividad de Fructuoso a mitad del siglo VII en el Bierzo. Los monasterios son el instrumento mejor adaptado a estas zonas de inercia arcaizante e indígena ${ }^{145}$. Su número podría ser mucho mayor del que pensamos, dada su forma a veces de simple agrupación vecinal o aldeana. En todo caso, no se trata nunca de aislamiento absoluto, un tópico que no parece tener fundamento. Incluso si analizamos las fundaciones de San Fructuoso en el Bierzo observaremos una relación estratégica con las vías de comunicación de entrada a Galicia desde la Meseta. Podemos pensar que, en su mayoría se crean ya en el propio siglo VIII, como ocurriría en los casos de Mosteiro o quizá Soutomerille ${ }^{146}$.

En ambas áreas podríamos ver, mezclándose con distinta intensidad, dos influencias principales en este monacato: uno de carácter latinoorientalizante, como el que encabeza la sede de Dumio, y otro de influencia atlántica-insular, representado por Bretoña ${ }^{147}$. De este modo en Galicia observamos un interesante cruce de influencias, un área de confín, entre dos concepciones de la vida cenobítica, que conducen a una forma peculiar de monacato, que es el pactualista con predominio de monasterios familiares ${ }^{148}$. También en otras áreas atlánticas con base de romanización, como Bretaña ${ }^{149}$ o Inglaterra suroriental ${ }^{150}$, se observa esta mezcla de influencias.

Este proceso de fundación de monasterios seguirá en los siglos IX y X, aunque a menudo ya a una escala diferente, en la órbita de poderes supralocales y en el contexto de avance del Reino Astur-Leonés y de la «Repoblación». De hecho ya a finales del siglo VIII tenemos algunos ejemplos en el entorno de Lugo de este nuevo contexto en la fundación de monasterios como Calvor en el 785 o la restauración previa de Samos, ambos relacionados con la nueva monarquía. Se trata en todo caso de un fenómeno que inaugura una nueva etapa, a cuyas puertas acaba nuestro trabajo.

145 Díaz, VII (Murcia, 1990); 2001.

146 ARES VÁZQUEZ, 1984: 123.

147 CANTERA y RODRÍGUEZ, LIV/120 (Santiago, 2007). WOOD, 2006: 151.

${ }^{148}$ FREIRE, 1998: 280

149 GUIGON, 2009: 173-190.

150 BLAIR, 2005: 73-76. 


\section{CONCLUSIÓn}

El estudio de las iglesias galaicas de los siglos V-VIII en su contexto arqueológico, geográfico e histórico saca a la luz un panorama que va mucho más allá de la simple idea de oscuridad y decadencia. Se trata más bien de una etapa compleja y con importantes procesos de fondo que la recorren en constante definición y redefinición. En ese sentido, el noroeste peninsular no es una excepción ni un ejemplo de aislamiento de las tendencias globales que recorren Europa en estos siglos. Más bien supone un caso más de la heterogeneidad que define dicho período ${ }^{151}$. De hecho es necesario recordar las importantes diferencias que encontramos entre áreas dentro de la propia Galicia, que impiden cualquier generalización fácil. La distinción entre zonas centrales y periféricas es útil, pero resulta aún más precisa si hablamos de una graduación entre ambos extremos. Debemos, por tanto, avanzar hacia un retrato más complejo y articulado de estos procesos, y las iglesias son un indicador válido para ello.

Entre los siglos V, VI e inicios del VII, la periférica Gallaecia experimenta una simbiosis de influencias, con distintos grados de aislamiento y de apertura conviviendo y retroalimentándose. Se trata de un área que mantiene, proporcionalmente, más dinamismo económico que otras zonas centrales, debido precisamente a esa situación externa y a la menor dependencia del sistema romano campo-ciudad. En este contexto se desarrolla una etapa de apogeo de dinámicas de poderes supralocales representados principalmente por los obispos y las jerarquías eclesiásticas. Se trata de grupos que se beneficiaron del proceso de polarización social y económica de este período y parte de su poder se materializa y se consolida también a través de la creación de iglesias en los ámbitos más romanizados y mejor comunicados, especialmente en la costa.

Sin embargo, a partir de mediados del siglo VII, este relativo dinamismo tardorromano parece agotarse y el protagonismo se traslada a la esfera local. Se trata de un proceso de fragmentación sociopolítica, con muchos grados y diferencias zonales, y tiene su reflejo físico en algunos reajustes en el paisaje. En este contexto de cambio, algunas élites encuentran huecos en los que afirmar su pequeño pero creciente poder y una de las estrategias de consolidación del mismo será la creación de pequeños monasterios, que acumulan y estabilizan patrimonios dispersos. Éstos, que inicialmente aparecen todavía en las zonas centrales, empezarán a extenderse a áreas más periféricas desde finales del siglo VII. Este contexto corresponde al inicio de un proceso general europeo de más amplio respiro, bien estudiado por C. Wickham, que se puede encuadrar como el «largo siglo VIII».

151 WICKHAM, 2005: 825. 
Como hemos visto, Galicia constituye un interesante laboratorio para explorar simbiosis y procesos sociopolíticos a distintas escalas en este período. A pesar de la problemática de los datos, el número de iglesias creadas durante este período en este territorio no parece desdeñable, y nos informa de una base de edificaciones eclesiásticas ya existente antes del auge de los siglos IX-XI, lo que debe hacernos reflexionar sobre el mito de los factores «exógenos» en la creación del Reino Astur Leonés y el avance de la «Reconquista». En todo caso aún quedan múltiples cuestiones sobre las que avanzar la investigación. Entre otras muchas, sería muy importante conocer mejor el alcance del pago de rentas a las iglesias ya que en este temprano período, la fijación de las áreas de enterramiento o los procesos de legitimación y reuso simbólico del pasado romano en estas edificaciones. Estas y otras cuestiones nos ayudarán a precisar el retrato de las dinámicas sociopolíticas que se entrecruzan en las iglesias altomedievales.

\section{Bibliografía}

Ares Vázquez, N., "Inscripciones lucenses medievales en verso”, Boletín do Museo Provincial de Lugo, 2 (Lugo, 1984): 119-134.

Arias Vilas, F. y Villa Valdés, A., "El poblamiento romano en el territorio de los galaicos lucenses”, en C. Fernández Ochoa y P. García Díaz, Unidad y diversidad en el Arco Atlántico en época romana, Oxford, Archaeopress, 2005; 297-308.

Arias Vilas, F., “A transición do mundo galaico-romano ó Reino dos Suevos”, en X. García Iglesias, Galicia castrexa e romana, Santiago, Consellería de Cultura, 1997; 289-297.

Arias Vilas, F., A Romanización de Galicia, Vigo, Galaxia, 1992.

Baliñas Pérez, C. y González Paz, C., "De Mailoc a san Rosendo: as orixes da sé mindoniense”, Rudesindus. A terra e o templo, Santiago, Xunta de Galicia, 2007.

Baliñas Pérez, C., "De Covadonga a Compostela: Galicia en el marco de la construcción del Reino de Asturias”, en La época de la Monarquía Asturiana: actas del simposio celebrado en Covadonga (8-10 de octubre de 2001), Oviedo, Universidad de Oviedo, 2002; 367-390.

Baliñas, C., Do mito á realidade, Santiago, Fundación Universitaria de Cultura, 1992.

Ballesteros Arias, P. "La Arqueología Rural y la construcción de un paisaje agrario medieval: el caso de Galicia”, en H. Kirchner, Por una arqueología agraria. Perspectivas de investigación sobre espacios de cultivo en las sociedades medievales hispánicas, Oxford, Archaeopress, 2010; 25-39.

Bell, T., The Religious Reuse of Roman Structures in Early Medieval England, Oxford, Archaeopress, 2005.

Blair, J., The Church in Anglo-Saxon Society, Oxford, Oxford University Press, 2005. 
Blanco-Rotea, R., Benavides García, R., Sanjurjo Sánchez, J. y Fernández Mosquera, D., "Evolución constructiva de Santa Eulalia de Bóveda (Lugo, Galicia)”, Arqueología de la Arquitectura, 6 (Madrid, 2009): 149-198.

Bowes, K., "Building Sacred Landscapes: Villas and Cult”, en A. Chavarría, J. Arce y G. P. Brogiolo, Villas tardoantiguas en el Mediterraneo Occidental, Madrid, CSIC, 2006; 73-95.

Brenk, B., "Spolia from Constantine to Charlemagne: Aesthetics versus Ideology”, Dumbarton Oaks Papers, 41 (1987); 103-109.

Brogiolo, G. P. y Chavarría, A., "Chiese, territorio e dinamiche del popolamento nelle campagne tra Tardoantico e Altomedioevo”, Hortus Artium Medievalium, 14 (Zagreb, 2008): 7-29.

Brogiolo, G. P. y Chavarría, A., Aristocrazie e campagne nell'Occidente da Costantino a Carlo Magno, Firenze, All’insegna del giglio, 2005.

Caballero, L. y Mateos, P., Visigodos y Omeyas: un debate entre la Antiguedad tardía y la Alta Edad Media, Madrid, CSIC, 2000.

Cantera, S. y Rodríguez, A., “Conciencia hispana y tradición monástica en la Vita Fructuosi”, Cuadernos de Estudios Gallegos, LIV/120 (Santiago, 2007): 71-102.

Carro Otero, J., “Moneda del rey D. Fernando II de Galicia-León y “ceca” compostelana”, Compostellanum, 3-4 (Santiago, 1987): 575-594.

Carro Otero, J., “Tres esqueletos de la necrópolis galaico-visigótica de San Xoao de Moraime (Muxía-La Coruña)”, Cuadernos de Estudios Gallegos, XXXVI/101 (Santiago, 1988): 7-53.

Castellanos, S. y Martín Viso, I., "The local articulation of central power in the north of the Iberian Peninsula”, Early Medieval Europe 13, (Londres, 2005): 1-42.

Castillo, A., “Un crismón del siglo V”, Boletín de la Real Academia Gallega, XV (A Coruña, 1925): 227-235.

Castiñeiras, M. A., “La reutilización de piezas romanas y medievales en Galicia”, Brigantium, 6 (A Coruña, 1990): 77-90.

Chamoso Lamas, M. y Filgueira Valverde, J. M., “Excavaciones arqueológicas en la iglesia y atrio de San Bartolomé de Rebordanes; de Tuy (Pontevedra)”, Noticiario Arqueológico Hispano. Arqueología, 4 (Madrid, 1976): 323-333.

Chamoso Lamas, M., “Avance informativo sobre las excavaciones realizadas en Bretoña (Lugo) durante las campaña de 1970 y 1971”, Noticiario Arqueológico Hispano. Prehistoria, 4 (Madrid, 1975): 265-271.

Chamoso Lamas, M., "Excavaciones arqueológicas en San Julian de Moraime (Mugía, La Coruña)”, Noticiario Arqueológico Hispánico, IV (Madrid, 1976): 335-350.

Chamoso Lamas, M., "Las primitivas Diócesis de Britonia y de San Martín de Mondoñedo a la luz de recientes descubrimientos”, Bracara Augusta, XXI (Braga, 1967): 356-360.

Chamoso Lamas, M., "Nuevas noticias sobre necrópolis paleocristianas y germánicas en Galicia”, Compostellanum, 16/1-4 (Santiago, 1971): 201-212. 
Chamoso Lamas, M., “Sobre las necrópolis paleocristianas ultimamente descubiertas en Galicia y Portugal”, Anuario de Estudios Medievales, II (Barcelona, 1965): 433-450.

Chavarria Arnau, A., Archeologia delle chiese, Roma, Carocci, 2009.

Chavarria Arnau, A., El final de las villae en Hispania (siglos IV-VII d. C.), Turnhout, Brepols, 2007.

Chavarria, A., “Chiese rurali in Hispania prima e dopo il 711: ipotesi su un'altra transizione”, en S. Gasparri, 774. Ipotesi su una transizione, Turnhout, Brepols, 2008; 313-327.

Chavarria, A., “Churches and aristocracies in seventh-century Spain”, Early Medieval Europe, 18/2 (Londres, 2010): 160-174.

Costa García, J. y Varela Gómez, D., “A Cidadela después de Roma: introducción al estudio del yacimiento y su entorno durante el periodo medieval”, Gallaecia, 30 (Santiago, 2011): 181-194.

Cunliffe, B., Facing the Ocean. The Atlantic and its Peoples, Oxford, Oxford University Press, 2001.

D’Emilio, J., “The legend of bishop Odoario and the Early Medieval Church in Galicia”, en T. Martin y J. A. Harris, Church, State, Vellum and Stone: Essays on Medieval Spain in Honor of John Williams, Boston, Brill, 2005; 47-83.

David, P., Études historiques sur la Galice et le Portugal du VIe au XIIe siècle, Coimbra-Paris, Institut Français au Portugal, 1947.

Davies, W., "Economic change in Early Medieval Ireland: the case for growth", en L'Irlanda e gli irlandesa nell'alto medioevo. LVII Settimana di studio del Centro Italiano di Studi sull'Alto Medioevo, Spoleto, CISAM, 2009; 111-132.

Delgado Gómez, J., “O conxunto paleocristián de Temes”, en Xunta de Galicia, Galicia castrexa e romana, Santiago de Compostela, Xunta de Galicia, 1997; 298-303.

Díaz Martínez, P. C., “Acuñación monetaria y organización administrativa en la Gallaecia tardoantigua”, Zephyrus, 57 (Salamanca, 2004): 367-375.

Díaz Martínez, P. C., "El alcance de la ocupación sueva de Gallaecia y el problema de la germanización”, en Galicia: da romanidade á xermanización. Problemas históricos e culturais, Santiago, Museo do Pobo Galego, 1993; 209-226.

Díaz Martínez, P. C., “El Parrochiale suevum: organización eclesiástica, poder político y poblamiento en la Gallaecia tardoantigua”, en J. Mangas, J. Alvar, y J. M. Blázquez, Homenaje a José María Blázquez, Madrid, Ediciones Clásicas, 1994; 35-47.

Díaz Martínez, P. C., “Extremis mundi partibus. Gallaecia tardoantigua”, en U. Espinosa y S. Castellanos, Comunidades locales y dinámicas de poder en el norte de la Península Ibérica durante la Antigüedad Tardía, Logroño, Universidad de la Rioja, 2006; 201-215.

Díaz y Díaz, M. C., “La cristianización en Galicia”, en La romanización de Galicia, Sada, Ediciós do Catro, 1992; 105-120. 
Díaz, P. C, “El monacato y la cristianización del NO. hispano”, Antigüedad y cristianismo, VII (Murcia, 1990): 531-539.

Díaz, P. C., “Gallaecia: de reino suevo a provincia visigoda”, en Galicia fai dous mil anos. O feito diferencial galego. I. Historia, Santiago, Museo do Pobo Galego, 1997; 233-278.

Díaz, P. C., “Monasteries in a peripherical area: seventh-century Gallaecia”, en M. Jong y F. Theuws, Topographies of Power in the Early Middle Ages, Leiden, Brill, 2001; 329-359.

Effros, B., "Monuments and memory: repossesing ancient remains in early medieval Gaul”, en: M. Jong y F. Theuws, Topographies of Power in the Early Middle Ages, Leiden, Brill, 2001; 93-118.

Escalona Monge, J., "Patrones de fragmentación territorial”, en U. Espinosa y S. Castellanos, Comunidades locales y dinámicas de poder en el norte de la Península Ibérica durante la Antigüedad Tardía, Logroño, Universidad de la Rioja, 2006; 165-199.

Espinosa, U. y Castellanos, S., Comunidades locales y dinámicas de poder en el norte de la Península Ibérica durante la Antigüedad Tardía, Logroño, Universidad de la Rioja, 2006.

Fariña Busto, F., de la Peña Santos, A. y Sierra, J. C., "Restos de una villa romana en Hío”, Museo de Pontevedra, 29 (Pontevedra, 1975): 175-186.

Fernández Fernández, A., “As relacións externas da Gallaecia durante os séculos IVVII d. C. a traversa do material importado localizado en Vigo (Galiza)”, en: F. Pérez Losada, Hidacio de Limia e o seu tempo: a Gallaecia sueva / A Limia na época medieval, Xinzo de Limia, Concello de Xinzo, 2011; 1-43.

Fixot, M., "Les lieux de culte et le terroir du village”, en M. Fixot y E. Zadora, L'église, le terroir, Paris, CNRS, 1989; 17-19.

Francovich, R. y Hodges, R., Villa to Village: the Transformation of the Roman Countryside in Italy, c. 400-1000, London, Duckworth, 2003.

Freire, J., El monacato gallego en la Alta Edad Media, A Coruña, Fundación Barrié de la Maza, 1998.

García y García, A., Historia de Bretoña, Lugo, Diputación de Lugo, 2000.

Gómez Sobrino, J., González Santiso, A. y Martínez do Tamuxe, X., "La villa romana y necrópolis germánica de Currás-Tomiño”, Tuy. Museo y Archivo Histórico y Diocesano, 3 (Ourense, 1980): 321-338.

González Millán, A. J., “El sarcófago paleocristiano de Portosín”, en X. García Iglesias, Galicia románica e gótica, Santiago, Consellería de Cultura, 1997; 32-37.

Guigon, P., “The Archaeology of the so-called 'Celtic Church' in Brittany”, en N. Edwards, The Archaeology of the Early Medieval Celtic Churches, Society for Medieval Archeology Monograph 29/Society for Church Archeology Monograph 1, Leeds, Maney, 2009; 173-190. 
Halsall, G., Settlement and Social Organisation. The Merovingian Region of Metz, Cambridge, Cambridge University Press, 1995.

Hamerow, H., Early Medieval settlements. The Archeology of Rural Communities in North-West Europe 400-900, Oxford, Oxford University Press, 2002.

Härke, H., “Cemeteries as places of power”, en M. Jong y F. Theuws, Topographies of Power in the Early Middle Ages, Leiden, Brill, 2001: 9-30.

Isla Frez, A., "El lugar de habitación de las aristocracias en época visigoda, siglos VI-VIII”, Arqueología y territorio medieval, 14 (Jaen, 2007): 9-19.

Isla Frez, A., La sociedad gallega en la Alta Edad Media, Madrid, CSIC, 1992.

Kirchner, H., "Sobre la arqueología de las aldeas altomedievales”, Studia historica. Historia Medieval, 28 (Salamanca, 2010): 243-253.

Le Jan, R., “Convents, violence and competition for power in seventh-century Francia”, en M. Jong y F. Theuws, Topographies of Power in the Early Middle Ages, Leiden, Brill, 2001; 243-269.

Lebecq, S., "The role of the monasteries in the systems of production and exchange of the Frankish world”, en I. Lyse Hansen y C. Wickham, The Long Eighth Century. Production, Distribution and Demand, Leiden, Brill, 2000; 121-148.

López Alsina, F., La ciudad de Santiago en la Alta Edad Media, Santiago, Ayuntamiento, 1988.

López Pereira, E., “Literatura en Gallaecia ata a invasión árabe”, en Galicia: da romanidade á xermanización. Problemas históricos e culturais, Santiago, Museo do Pobo Galego, 1993; 415-425.

López Quiroga, J., El final de la antigüedad en la Gallaecia, A Coruña, Fundación Barrié de la Maza, 2004.

Lyse Hansen, I. y Wickham, C., The Long Eighth Century. Production, Distribution and Demand, Leiden, Brill, 2000.

Manzano Moreno, E., “La conquista del 711: transformaciones y pervivencias“, en L. Caballero y P. Mateos, Visigodos y Omeyas: un debate entre la Antiguedad tardía y la Alta Edad Media, Madrid, CSIC, 2000; 401-414.

Morris, R., Churches in the Landscape, London, Phoenix, 1997.

Novo Guisán, J. M., Los pueblos vascos-cantábricos y galaicos en la antigüedad tardía: siglos III-IX, Alcalá de Henares, Universidad de Alcalá, 1992.

Núñez Rodríguez, M., Arquitectura prerrománica, Santiago, COAG, 1978.

Núñez, O. y Cavada, M., El nacimiento del cristianismo en Gallaecia, Ourense, Aica, 2001.

Ó Carragáin, T., Churches in Early Medieval Ireland. Architecture, Ritual and Memory, New Haven, Yale University Press, 2010.

Pallares, M. C y Portela, E. (1997b), “Galicia á marxe do Islam. Continuidade das estructuras organizativas no tránsito á Idade Media”, en G. Pereira, Galicia fai dous mil anos, Santiago, Museo do Pobo Galego, 1997; 435-458. 
Pérez Losada, F., Entre a cidade e a aldea, A Coruña, Museo Arqueológico de A Coruña, 2002.

Quirós Castillo, J. A. (ed.), The Archaeology of Early Medieval Villages in Europe, Bilbao, Universidad del País Vasco, 2009.

Quirós Castillo, J. A., “Las iglesias altomedievales en el País Vasco. Del monumento al paisaje”, Studia Histórica. Historia Medieval, 29 (Salamanca, 2011): 175-205.

Ramil González, E., “Villa romana de Bares”, Brigantium, 14 (A Coruña, 2003): 185-224.

Rivas Fernández, J. C., Antigüedad del episcopado auriense, Ourense, Duen de Bux, 2003.

Rodríguez Colmenero, A., “Excavaciones arqueológicas en Ouvigo, Blancos (Orense)”, Noticiario Arqueológico Hispano, 24 (Madrid, 1985): 265-387.

Rodríguez Colmenero, A., "Historia del arte romano de Galicia” en J. M. Vázquez Varela, A. Rodríguez Colmenero, Arte Prehistórico y Romano, A Coruña, Hércules, 1993, t. IX; 413-414.

Rodríguez Colmenero, A., Ferrer Sierra, S. y García Tato, I., Priorato de Xagoaza (Valdeorras, Ourense): el referente histórico de una próspera comarca gallega, Ourense, Fundación Aquae Querquennae Via Nova, 2009.

Rodríguez Colmenero, A., Ferrer Sierra, S. y Álvarez Asorey, R., Miliarios e outras inscricións viarias romanas do Noroeste Hispánico (Conventos Bracarense, Lucense e Asturicense), Santiago, Consello da Cultura Galega, 2004.

Rodríguez Resino, A., Do imperio romano á Alta Idade Media. Arqueología da Tardoantigüidade en Galicia (séculos V-VIII), Noia, Toxosoutos, 2005.

Sánchez Pardo, J. C., “Castros y aldeas galaicorromanas: sobre la evolución y transformación del poblamiento indígena en la Galicia romana”, Zephyrus, LXV (Salamanca, 2010): 129-148.

Sánchez Pardo, J. C., "Los contextos de fundación de las iglesias tardoantiguas en Galicia (ss. V-VIII): substratos arqueológicos, distribución y significados”, Antiquité Tardive, 20 (París, 2012): 255-273.

Sánchez Pardo, J. C., "Poblamiento rural tardorromano y altomedieval en Galicia. Una revisión arqueológica”, Archeologia Medievale, XXXVII (Siena, 2010): 285-306.

Sánchez Pardo, J. C., "Powers and rural landscapes in Early Medieval Galicia. Towards a re-incorporation of Archaeology in the Historical Discourse”, Early Medieval Europe, (Londres, en prensa).

Suárez Otero, J., “Crismón de San Pedro de Leis”, en Singul, F. y Suárez, J. (eds.), Até o confín do mundo: diálogos entre Santiago e o mar, Vigo, Galaxia, 2004; 91. Suárez Otero, J., “Iria, Padrón, Santiago. Geografía mítica y realidad arqueológica”, en V. Almazán, Padrón, Iria y las tradiciones jacobeas, Santiago, Xunta de Galicia, 2004; 245-272.

Torres Rodríguez, C., Galicia sueva, A Coruña, Fundación Barrié, 1977. 
Turner, S., Making a Christian Landscape. The Countryside in Early Medieval Cornwall, Devon and Wessex, Exeter, University of Exeter Press, 2006.

Utrero, M. A., "Late-Antique and Early Medieval Hispanic Churches and the Archaeology of Architecture”, Medieval Archaeology, 54 (Londres, 2010): 1-33.

Wickham, C., "Overview: production, distribution and demand, II", en I. Lyse Hansen y C. Wickham, The Long Eighth Century. Production, Distribution and Demand, Leiden, Brill, 2000.

Wickham, C., Framing the Early Middle Ages. Europe and the Mediterranean, 400800, Oxford, Oxford University Press, 2005.

Wood, S., The Proprietary Church in the Medieval West, Oxford, Oxford University Press, 2006.

Yzquierdo Perrín, R., Arte Medieval (I), A Coruña, Hércules, 1993.

Zadora Rio, E., "L'historiographie des paroisses rurales à l'épreuve de l'archéologie”, en C. Delaplace, Aux origines de la paroisse rurale en Gaule Méridionale (IVe IXe siècles), Paris, Errance, 2005; 15-23.

Recibido: 26-04-2011

Aceptado: 10-05-2012 